\title{
Water properties and circulation in Arctic Ocean models
}

\author{
G. Holloway, ${ }^{1}$ F. Dupont, ${ }^{2}$ E. Golubeva,${ }^{3}$ S. Häkkinen, ${ }^{4}$ E. Hunke, ${ }^{5}$ M. Jin, ${ }^{6}$ M. Karcher, ${ }^{7,8}$ \\ F. Kauker, ${ }^{7,8}$ M. Maltrud, ${ }^{5}$ M. A. Morales Maqueda, ${ }^{9}$ W. Maslowski, ${ }^{10}$ G. Platov, ${ }^{3}$ \\ D. Stark, ${ }^{10}$ M. Steele, ${ }^{11}$ T. Suzuki, ${ }^{12}$ J. Wang, ${ }^{6}$ and J. Zhang ${ }^{11}$
}

Received 13 April 2006; revised 18 July 2006; accepted 10 August 2006; published 7 March 2007.

[1] As a part of the Arctic Ocean Model Intercomparison Project, results from 10 Arctic ocean/ice models are intercompared over the period 1970 through 1999. Models' monthly mean outputs are laterally integrated over two subdomains (Amerasian and Eurasian basins), then examined as functions of depth and time. Differences in such fields as averaged temperature and salinity arise from models' differences in parameterizations and numerical methods and from different domain sizes, with anomalies that develop at lower latitudes carried into the Arctic. A systematic deficiency is seen as AOMIP models tend to produce thermally stratified upper layers rather than the "cold halocline", suggesting missing physics perhaps related to vertical mixing or to shelf-basin exchanges. Flow fields pose a challenge for intercomparison. We introduce topostrophy, the vertical component of $\mathbf{V} \times \boldsymbol{\nabla D}$ where $\mathbf{V}$ is monthly mean velocity and $\boldsymbol{\nabla D}$ is the gradient of total depth, characterizing the tendency to follow topographic slopes. Positive topostrophy expresses a tendency for cyclonic "rim currents". Systematic differences of models" circulations are found to depend strongly upon assumed roles of unresolved eddies.

Citation: Holloway, G., et al. (2007), Water properties and circulation in Arctic Ocean models, J. Geophys. Res., 112, C04S03, doi:10.1029/2006JC003642.

\section{Participating Models}

[2] The Arctic Ocean Model Intercomparison Project (AOMIP) brings together efforts from 15 Arctic Ocean modeling groups in 9 countries to evaluate differences among model outputs and differences between models and observations. The aim is to improve capability to model the Arctic ocean/ice system. An overview of AOMIP, including protocols for common initialization and forcing can be seen at http://fish.cims.nyu.edu/project_aomip/overview.html and at http://www.planetwater.ca/research/AOMIP. Detailed specifications for AOMIP models are given in Appendix A.

\footnotetext{
${ }^{1}$ Institute of Ocean Sciences, Department of Fisheries and Oceans, Sidney, British Columbia, Canada.

${ }^{2}$ Quebec-Ocean, Université Laval, Sainte-Foy, Québec, Canada.

${ }^{3}$ Institute of Computational Mathematics and Mathematical Geophysics, Siberian Branch of Russian Academy of Sciences, Novosibirsk, Russia.

${ }^{4}$ NASA Goddard Space Flight Center, Greenbelt, Maryland, USA.

${ }^{5}$ Climate, Ocean, and Sea Ice Modeling Program, Los Alamos National Laboratory, Los Alamos, New Mexico, USA.

${ }^{6}$ International Arctic Research Center, University of Alaska Fairbanks, Fairbanks, Alaska, USA.

${ }^{7}$ O. A. Sys. - Ocean Atmosphere Systems GbR, Hamburg, Germany.

${ }^{8}$ Also at Alfred Wegener Institute for Polar and Marine Research, Bremerhaven, Germany.

${ }^{9}$ Proudman Oceanographic Laboratory, Liverpool, U.K.

${ }^{10}$ Department of Oceanography, Naval Postgraduate School, Monterey, California, USA.

${ }^{11}$ Applied Physics Laboratory, University of Washington, Seattle, Washington, USA.

${ }^{12}$ Frontier Research Center for Global Change, Yokohama, Kanagawa, Japan.
}

Copyright 2007 by the American Geophysical Union. 0148-0227/07/2006JC003642\$09.00
Although an AOMIP goal is to attempt to execute the different models under as conditions similar as possible, Appendix A reveals how difficult this goal is given the many choices all modelers must make.

[3] The present study focuses on water properties and circulation. Related studies addressing sea ice properties and motion are seen in Johnson et al. [2007] or Martin and Gerdes [2007].

[4] Ten of the AOMIP modeling groups participated in the present study. These are as follows: AWI, Alfred Wegener Institute - Bremerhaven, Germany; CNF, Frontier Research Center for Global Change, Japan, with International Arctic Research Center, USA; GSFC, NASA Goddard Space Flight Center, USA; ICMMG, Institute of Computational Math. and Math. Geophysics, Russia; IOS, Institute of Ocean Sciences, Canada; LANL, Los Alamos National Laboratory, USA; NPS, Naval Postgraduate School, USA; POL, Proudman Oceanographic Laboratory, Liverpool, UK; UL, Universite Laval, Quebec, Canada; UW, University of Washington, USA.

\section{MIP Analysis Domains}

[5] Model intercomparisons face many obstacles. Different models compute in different domains ranging from limited regions to global. Procedures for initializing and forcing vary. AOMIP has sought to narrow the range of external differences by establishing, so far as possible, common protocols for initialization and for atmospheric and riverine forcing. Model resolutions, methods of discretization, internal parameterizations, and specifications on open lateral boundaries are left to the choices of the different modeling groups. 


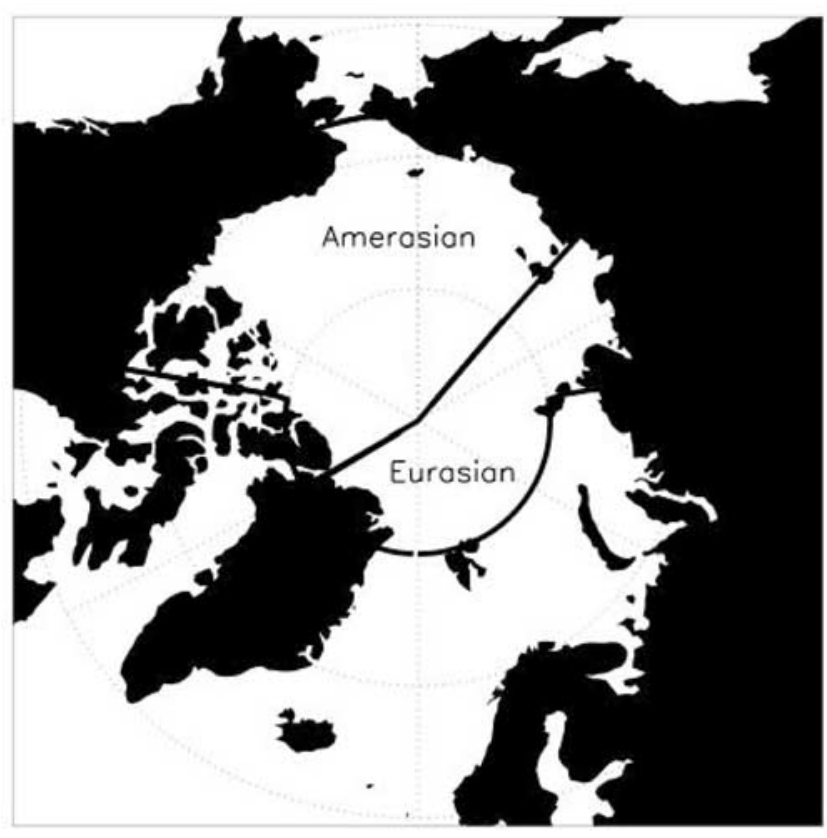

Figure 1. Analysis subdomains are the Amerasian ("A") and Eurasian ("E") basins.

[6] At this stage of AOMIP, the main goal is to identify differences among models and between models and observations. A challenge arises in choosing what aspects of model output to intercompare. Models produce vast numerical output, with $\mathrm{O}\left(10^{7}\right)$ variables defining the model states which might be examined $\mathrm{O}\left(10^{4}\right)$ times during a 50 year integration. To make feasible intercomparison among the vastness of models' outputs, we examine integrated measures. For this purpose we divide the Arctic into two subdomains, labeled "A" (Amerasian basins) and "E" (Eurasian basins) as seen in Figure 1. Together "E" and "A" are defined by $\phi>80 \mathrm{~N}$ for $\lambda>260 \mathrm{E}$ and $\lambda<100 \mathrm{E}$, then by $\phi>66 \mathrm{~N}$ for $\lambda>100 \mathrm{E}$ to $\lambda<260 \mathrm{E}$. Subdomains "A" and "E" are then separated along 140E and 300E.

[7] The remainder of this paper reflects the present status of, and the process of, AOMIP. The following section, "MIP Diagnostics", exhibits differences among models and from observations with minimal discussion. A subsequent "Discussion" expresses preliminary remarks and interpretations. A "Summary" concludes the paper.

\section{MIP Diagnostics}

\subsection{Water Properties}

[8] With atmospheric forcing given in part from NCAR/ NCEP Reanalysis [Kalnay et al., 1996], the period for AOMIP evaluation is from January 1948 until present. Because of uncertainties in initialization and differing termination dates for different models, the intercomparison here reported is based upon monthly averages of models' outputs during the 30 year period January 1970 through December 1999. Importantly for the present study, none of the models employ surface layer restoring during 1970 through 1999. Some, but not all, models employed restoring during a spin-up period 1948 through 1958.

[9] Figures $2 \mathrm{a}$ and $2 \mathrm{~b}$ show potential temperature, $\theta$, for each model (referenced to sea surface) over 0 to $1500 \mathrm{~m}$ depth from 1970 through 1999, laterally averaged over "E"

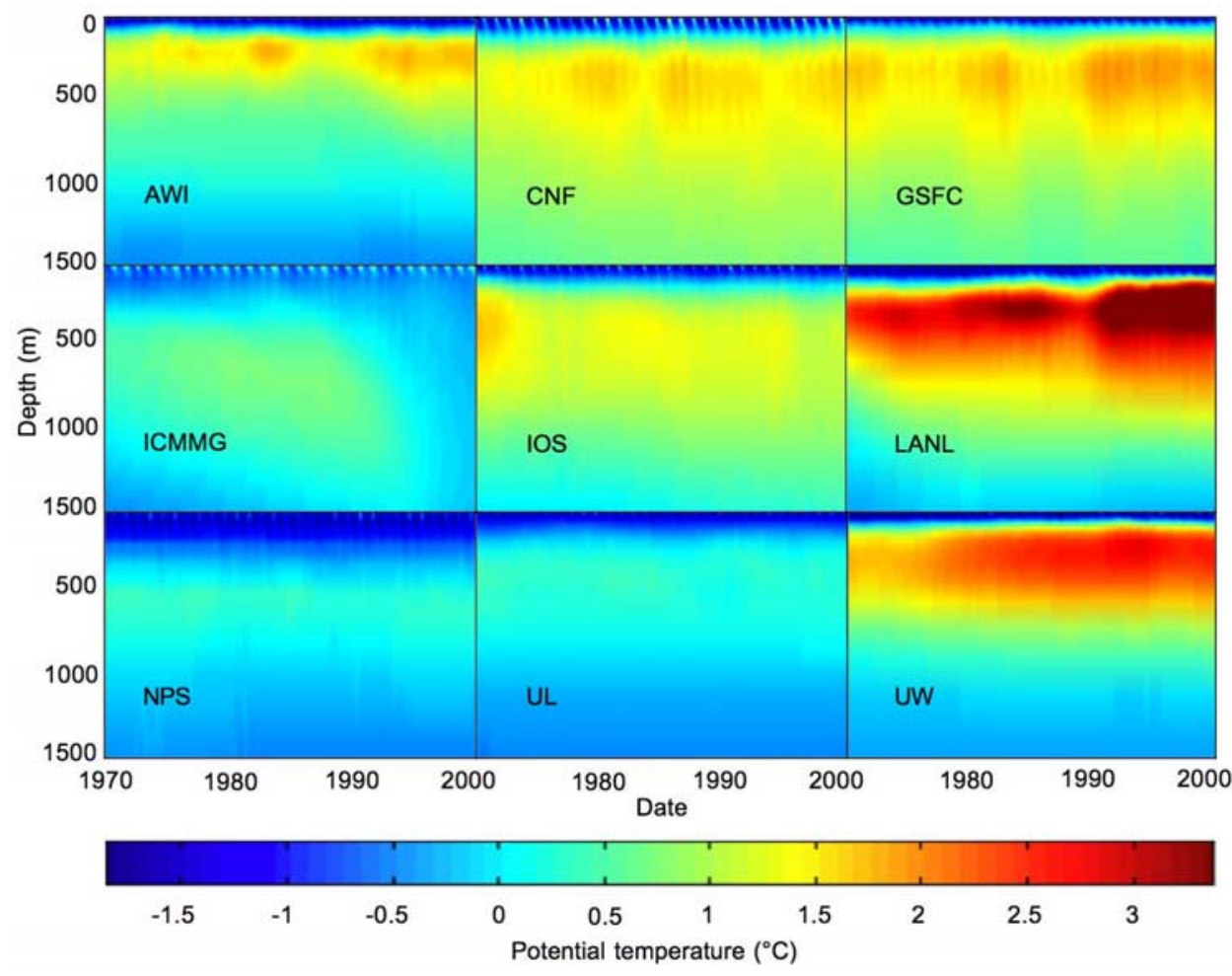

Figure 2a. Monthly mean potential temperature $\left({ }^{\circ} \mathrm{C}\right)$ is shown as a function of depth and time for models AWI, CNF, GSFC, ICMMG, IOS, LANL, NPS, UL and UW averaged over subdomain "E”. 


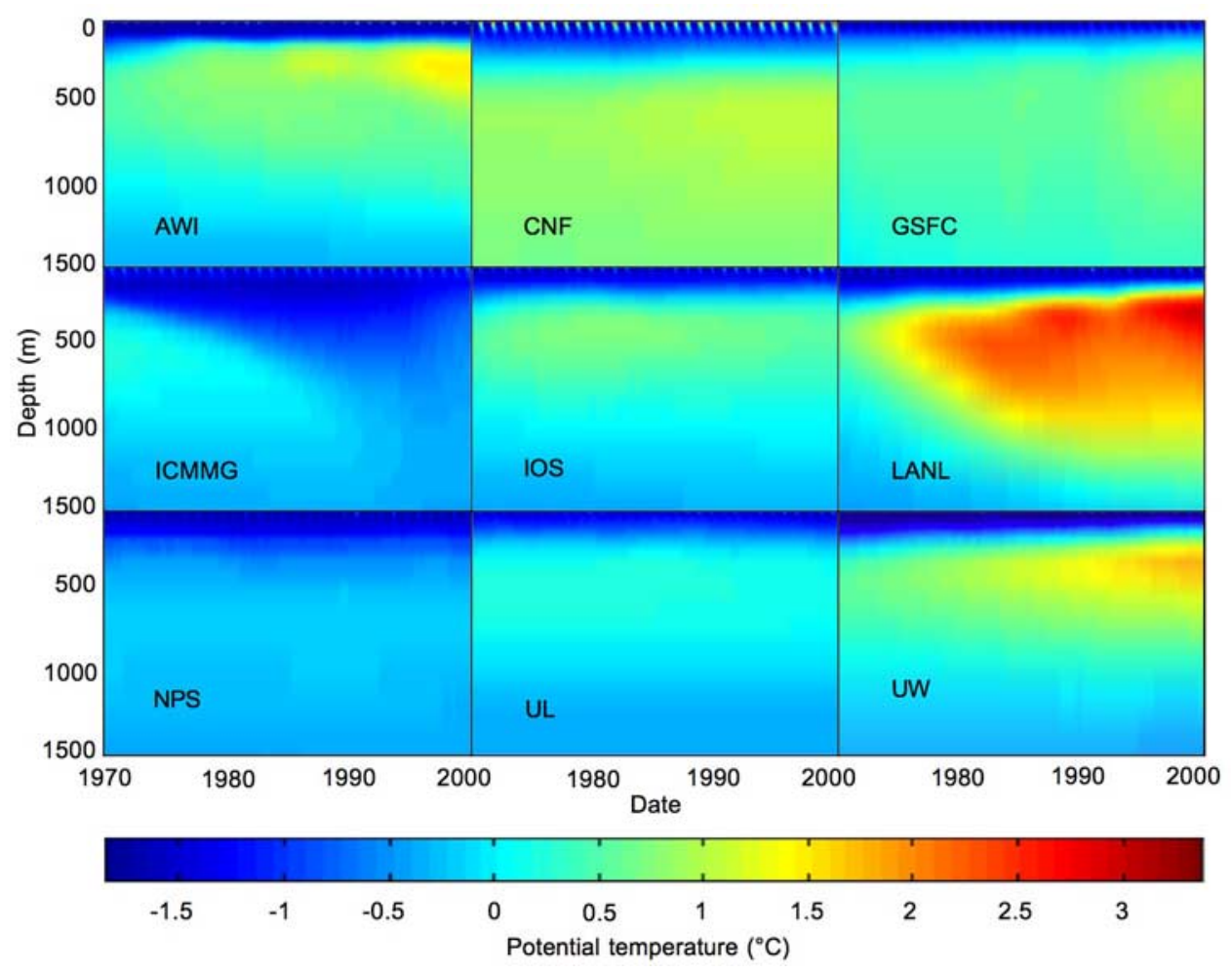

Figure 2b. Monthly mean potential temperature $\left({ }^{\circ} \mathrm{C}\right)$ is shown as a function of depth and time for models AWI, CNF, GSFC, ICMMG, IOS, LANL, NPS, UL and UW averaged over subdomain "A".

and "A" subdomains. Nine of the models" results are displayed. For this section, model POL (not shown) is nearly identical to IOS (shown). In subsequent discussion of water properties, results from the POL model are shown concerning sensitivities to numerical methods.

[10] A common colorbar has been assigned for showing all models' results. Some results fall outside the colorbar range (Table 1).

[11] Figures $3 a-3 c$ show time series of total heat (full water column) in subdomains " $A$ " and " $E$ " for each of the models and also as estimated from decadal averages of observations from $E W G$ [1997, 1998]. In some cases the total heat seen in Figures $3 a-3 c$ reflects significant differences in model heat stored in depths greater than $1500 \mathrm{~m}$, hence not seen in Figures $2 \mathrm{a}$ and $2 \mathrm{~b}$. It should also be noted that extrema of $\theta$ can occur in very thin surface layers not clearly seen in Figures $2 \mathrm{a}$ and $2 \mathrm{~b}$ over 0 to $1500 \mathrm{~m}$.

[12] Whereas $\theta$ especially distinguishes the Atlantic Layer (occurring mainly in depth range 300 to $800 \mathrm{~m}$ ), salinity variations, $\mathrm{S}$, occur more in upper layers, exerting great influence as well as providing an important characteristic of Arctic models. For these reasons, and to better reveal $\mathrm{S}$ variations over the depth range within which $\mathrm{S}$ strongly varies, Figures $4 \mathrm{a}$ and $4 \mathrm{~b}$ show $\mathrm{S}$ over 0 to $300 \mathrm{~m}$, from 1970 through 1999, laterally averaged over subdomains " $\mathrm{A}$ " and "E". Some models' results fall outside the common colorbar range (Table 2).

[13] Figures 5a and 5b show time series of total freshwater (full water column), defined relative to $\mathrm{S}=34.8$ and integrated over subdomains " $A$ " and " $E$ " for each of the models and also as estimated from decadal averages of observations from $E W G$ [1997, 1998]. In some cases the total freshwater seen in Figures $5 \mathrm{a}$ and $5 \mathrm{~b}$ reflects significant differences in model freshwater stored in depths greater than $300 \mathrm{~m}$, hence not seen in Figures $4 \mathrm{a}$ and $4 \mathrm{~b}$.

\subsection{Flow Characteristics}

[14] Characterizing circulation patterns in terms of integral measures is difficult. On one hand, recent attention has focused on the sense of circulation, being more cyclonic or anticyclonic at Atlantic Layer depths, with models producing results of either sign [Proshutinsky et al., 2005]. Yet the basis for regarding any model result at any depth at any time as being more cyclonic or anticyclonic is often unclear. Impressions are gained from looking at velocity maps where, often within a single basin, some regions of flow seem more cyclonic, others more anticyclonic. Then it is not clear that broad terms like "cyclonic" are adequate (even if

Table 1. Ranges of $\theta$ for Each Model in Subdomains "E" and "A"

\begin{tabular}{lllllllllll}
\hline & & AWI & GSFC & CNF & ICM & IOS & LANL & NPS & UL & UW \\
\hline $\operatorname{Min} \theta$ & "E": & -1.87 & -1.86 & -1.78 & -1.14 & -1.80 & -1.84 & -1.69 & -1.77 & -1.96 \\
& "A": & -1.83 & -1.81 & -1.74 & -1.66 & -1.73 & -1.77 & -1.68 & -1.72 & -1.96 \\
$\operatorname{Max} \theta$ & "E": & 2.91 & 1.99 & 1.88 & 1.27 & 1.84 & 4.54 & 0.39 & 0.75 & 2.78 \\
& "A": & 1.46 & 0.94 & 3.33 & 0.24 & 0.73 & 3.05 & 0.03 & 0.41 & 1.88 \\
\hline
\end{tabular}




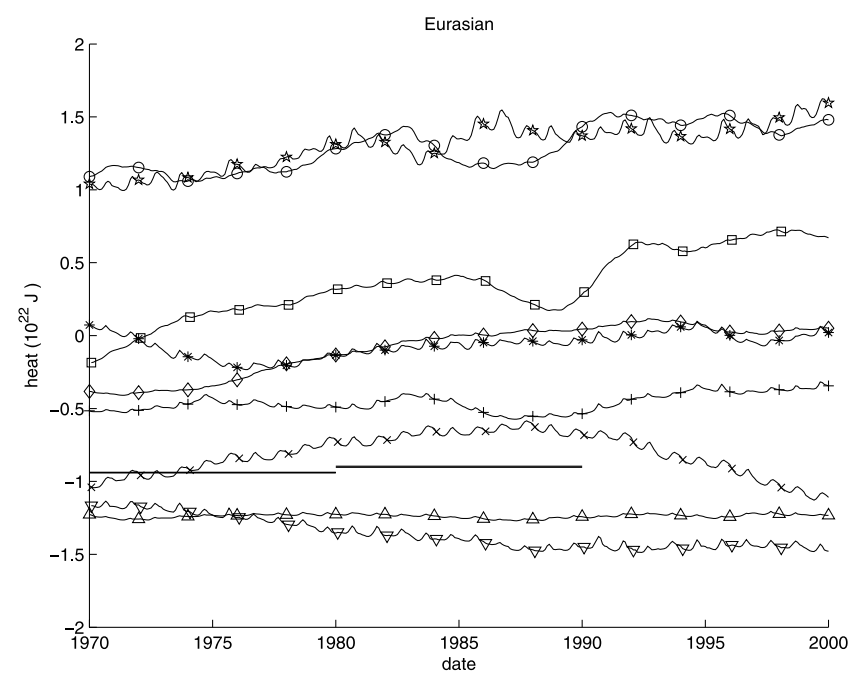

Figure 3a. Total heat referenced to $0^{\circ} \mathrm{C}$, integrated over the volume of subdomain " $\mathrm{E}$ ", is plotted in units of $10^{22} \mathrm{~J}$. Horizontal lines during the 1970 s and 1980s are decadal mean heat for subdomain "E" from $E W G$ [1997, 1998] summer and winter atlases.

they could be unambiguously assigned). A further concern is that real mid-depth flows may be rather tightly constrained to narrow "rim" currents as distinct from broader gyres.

[15] To avoid complicated vector fields, we examine topostrophy, a scalar field given by the upwards component $\tau=(\mathbf{V} \times \boldsymbol{\nabla D})^{\bullet} \mathbf{z}$ where $\mathbf{V}$ is velocity, $\boldsymbol{\nabla D}$ is the gradient of total depth and $\mathbf{z}$ is the unit vertical vector. In the northern hemisphere, flow with shallower water to the right is characterized by positive (upwards) $\tau$. As circumbasin rim currents, bands of positive $\tau$ express cyclonic sense.

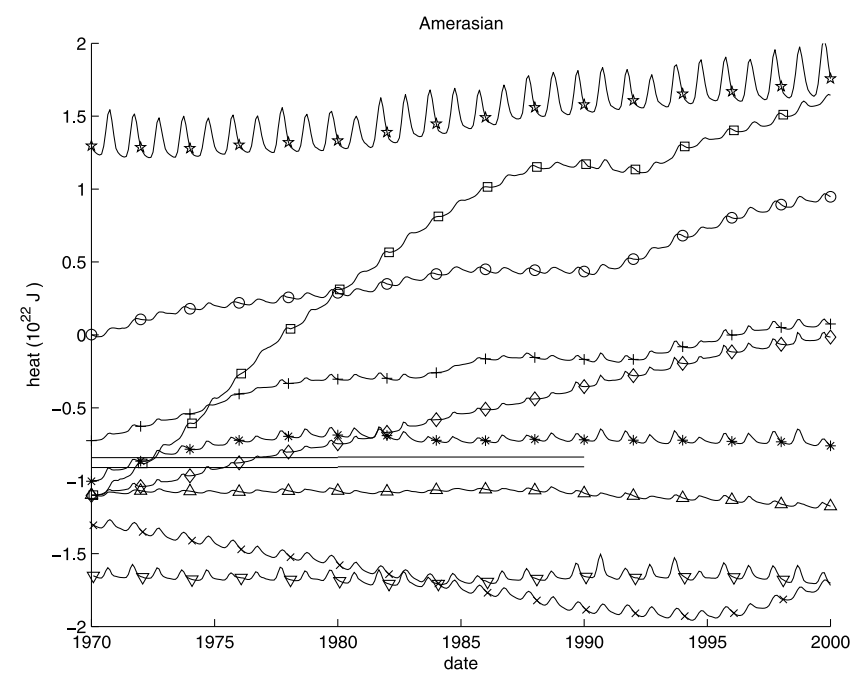

Figure 3b. Total heat referenced to $0^{\circ} \mathrm{C}$, integrated over the volume of subdomain " $\mathrm{A}$ ", is plotted in units of $10^{22} \mathrm{~J}$. Horizontal lines during the 1970s and 1980s are decadal mean heat for subdomain "A" from $E W G$ [1997, 1998] summer and winter atlases.
[16] Using model 'IOS', Figures $6 \mathrm{a}$ and $6 \mathrm{~b}$ illustrate $\tau$ for average flow during December 1987 at 180m depth from two cases which differ only by internal model parameters. These cases will be described later under 'Discussion' and are shown here only to illustrate how topostrophy can be used to characterize flows patterns.

[17] At each depth, $\tau$ is laterally averaged over subdomains "A" and "E", based on monthly averaged velocity fields. Figures $7 \mathrm{a}$ and $7 \mathrm{~b}$ show $\tau$ over depth range 0 to $1500 \mathrm{~m}$ nondimensionalized at each depth level by the product (speed) $\times$ (slope) where speed is the square root of horizontal average of $\mathbf{V} \cdot \mathbf{V}$ and slope is the square root of horizontal average of $\nabla D \cdot \nabla D$ (Table 3 ). Figures $8 \mathrm{a}$ and $8 \mathrm{~b}$ show time series of normalized $\tau$ averaged over the volumes of subdomains " $A$ " and "E".

[18] At Figures 9a and 9b we consider the lateral averages of speed of monthly averaged flow. The color scale is limited to speeds less than. $03 \mathrm{~m} / \mathrm{s}$ in order to reveal the depth and time structure of speeds down to $1500 \mathrm{~m}$. Two reasons for these figures are, first, to observe again the striking differences among models and, second, to provide information about amplitude of speed which, together with amplitude of bottom slope (Figure A2), allow further interpretation of $\tau$ that was shown normalized by speed and slope in Figures $7 \mathrm{a}$ and $7 \mathrm{~b}$ and Figures $8 \mathrm{a}$ and $8 \mathrm{~b}$. Speeds greater than. $03 \mathrm{~m} / \mathrm{s}$ occur mainly in surface layer flows (Table 4). Figures 10a and $10 \mathrm{~b}$ show total kinetic energy (full water column) integrated over subdomains " $A$ " and " $E$ " for each of the models.

\section{Discussion}

[19] Previous efforts [Proshutinsky et al., 2001; Steele et al., 2001; Steiner et al., 2004; Proshutinsky et al., 2005; Uotila et al., 2006] have already reported large differences among AOMIP models. However, during the earlier development of AOMIP, model experiments were performed in largely uncoordinated ways, differing in the manners of

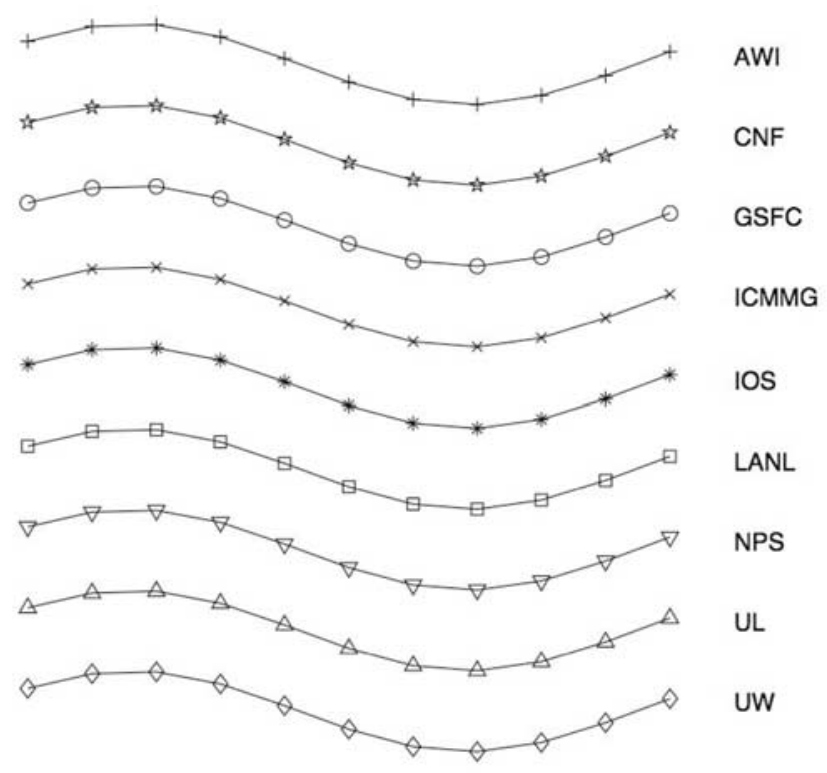

Figure 3c. Symbols identify the models. 


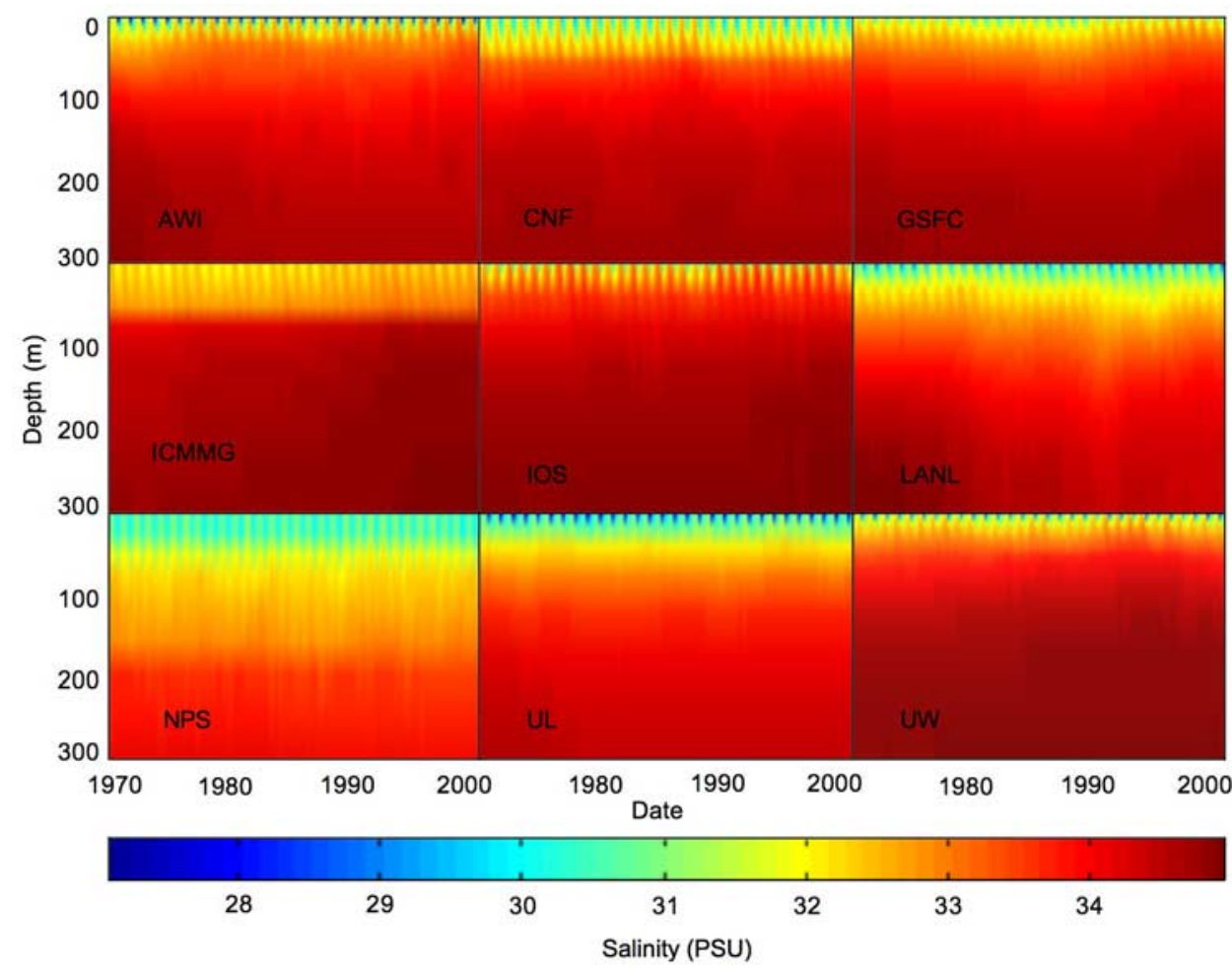

Figure 4a. Monthly mean salinity is shown as a function of depth and time for models AWI, CNF, GSFC, ICMMG, IOS, LANL, UL, NPS and UW averaged over subdomain "E”.

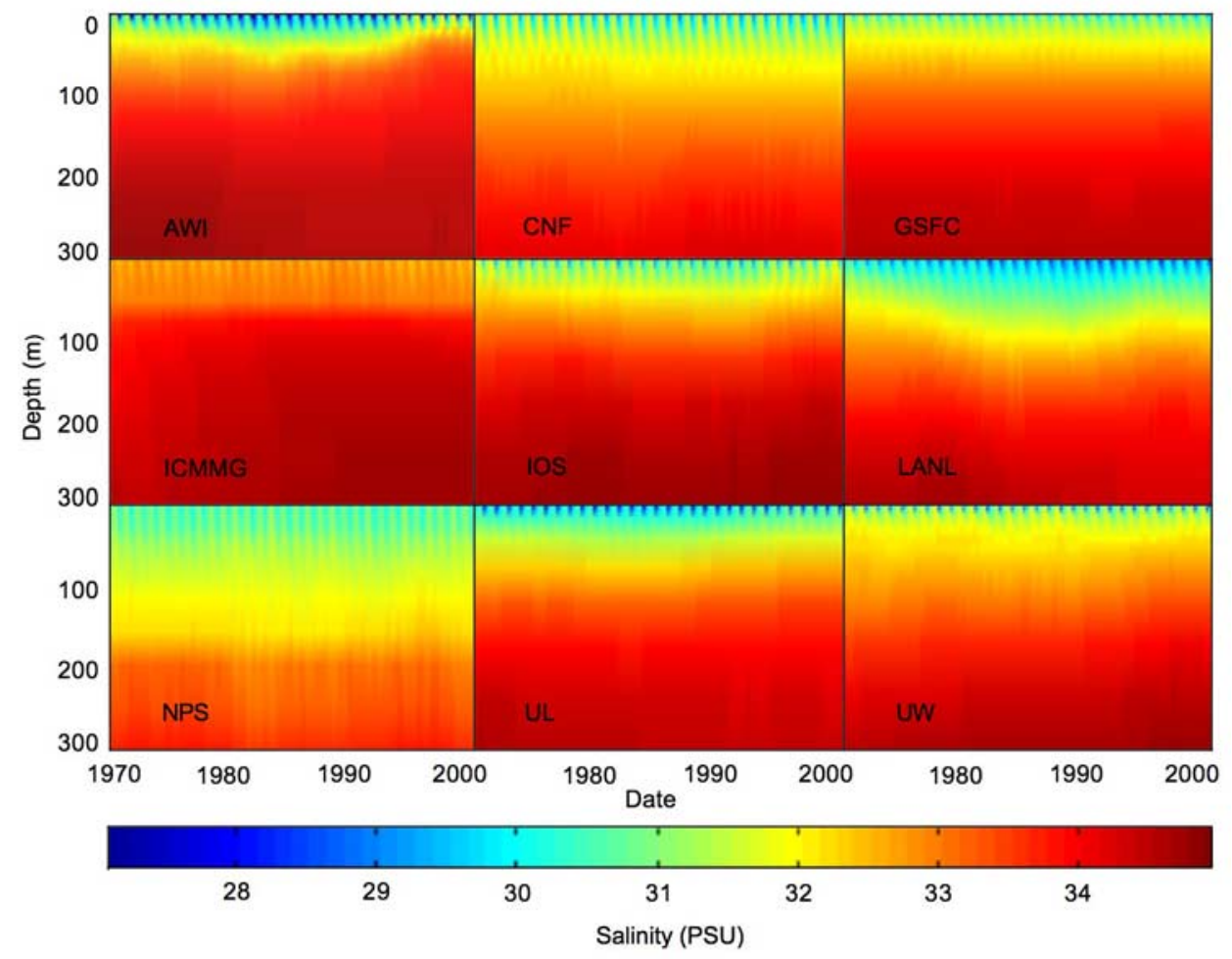

Figure 4b. Monthly mean salinity is shown as a function of depth and time for models AWI, CNF, GSFC, ICMMG, IOS, LANL, UL, NPS and UW averaged over subdomain "A". 
Table 2. Ranges of S for Each Model in Subdomains "E" and "A"

\begin{tabular}{|c|c|c|c|c|c|c|c|c|c|c|}
\hline & & AWI & GSFC & $\mathrm{CNF}$ & ICM & IOS & LANL & NPS & UL & UW \\
\hline \multirow[t]{2}{*}{$\operatorname{Min} \mathrm{S}$} & "E": & 26.33 & 29.68 & 29.22 & 31.77 & 29.06 & 28.41 & 29.84 & 27.31 & 27.76 \\
\hline & "A": & 25.27 & 28.98 & 28.85 & 32.31 & 28.52 & 27.42 & 29.97 & 27.36 & 27.85 \\
\hline \multirow[t]{2}{*}{ Max S } & "E": & 34.95 & 35.05 & 34.90 & 34.97 & 35.00 & 35.04 & 34.97 & 34.94 & 34.97 \\
\hline & "A": & 34.96 & 34.99 & 34.90 & 34.97 & 34.96 & 35.04 & 34.97 & 34.96 & 34.99 \\
\hline
\end{tabular}

initialization and of forcing as well as by differences of domain, grid size, model architecture, numerical methods and physical parameterizations. Interpretation of differences of models outputs was difficult. With progress toward higher coordination (not yet fully achieved) in aspects such as initialization and forcing, it has been hoped that differences among models results would diminish.

[20] Before turning to water properties and circulation, it is notable that large differences occur even in the assignments of models' bathymetries as summarized in Appendix A. Although bathymetric data is notionally accessed from a common source (but exceptions occur), and even when analysis domains are given precise latitude-longitude definitions, differences are seen in lateral area (Figure A1) and root mean square bottom slope (Figure A2) plotted as functions of depth. Such differences arise in parts due to different grid sizes, to numbers and placements of vertical levels, to methods of extracting/assigning depths, and to smoothing. At coarser resolution a $\sigma$-coordinate model (GSFC) employs significant smoothing to limit pressure gradient errors while another $\sigma$-coordinate model (CNF) on a finer grid with more vertical levels admits more bathymetric roughness. Likewise in $\mathrm{z}$-coordinates, models at finer resolutions tend to admit more bathymetric roughness.

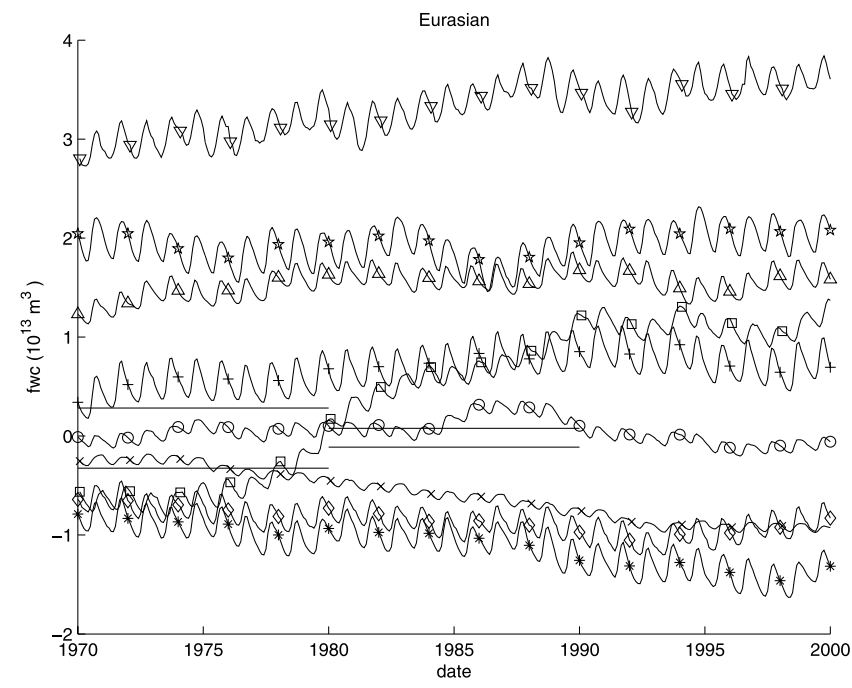

Figure 5a. Total freshwater referenced to $\mathrm{S}=34.8$ (including negative contributions when $\mathrm{S}>34.8$ ) is plotted in units of $1013 \mathrm{~m}^{3}$. Symbols are defined at Figures $3 a-3 c$. Horizontal lines during the 1970s and 1980s are decadal mean freshwater from $E W G$ [1997, 1998] summer and winter atlases integrated over the volume of subdomain "E".

\subsection{Water Properties}

[21] It may be perplexing that differences in such fundamental properties as averaged $\theta$ and $\mathrm{S}$ remain so large. Some models exhibit large long term drift in both $\theta$ and $\mathrm{S}$; others show relatively small drift. This can be due, in part, to domain size with a global model (LANL) yielding large drift that may be imported into the Arctic from lower latitudes. Hunke and Holland [2007] report that modifying the surface forcing in the LANL model, thereby increasing ocean cooling in the North Atlantic, reduces the amount of heat imported to the Arctic.

[22] The role of domain size and import of thermal or freshwater anomalies does not entirely explain models' differences which depend also upon differences in forcing and parameters within the Arctic. Roles of forcing are considered by Karcher et al. [2007] where drifting hydrography in the Arctic is discussed as a consequence of no restoring of sea surface salinity in the AOMIP experiments. Physics differences are seen, e.g., in the IOS model that includes effects of tides (absent from other models) which enhance ventilation of Atlantic heat [Holloway and Proshutinsky, 2007]. It is also to be noted that model CNF includes a dynamic atmosphere whereas other AOMIP models adopt assigned atmospheric variables.

[23] Comparison of model results with observations is complicated because direct observations are not available to make horizontally domain-averaged diagnostics on monthly

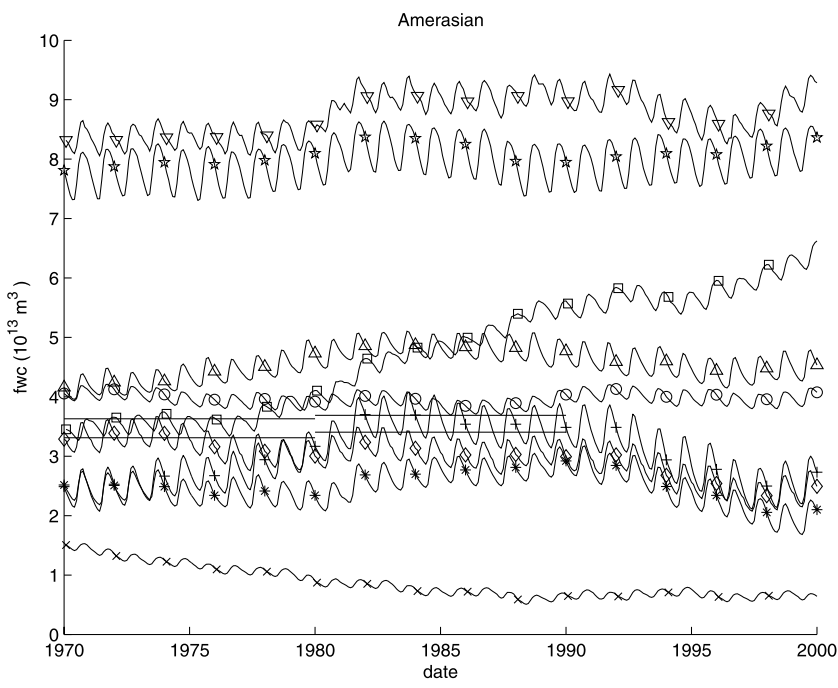

Figure 5b. Total freshwater referenced to $\mathrm{S}=34.8$ (including negative contributions when $\mathrm{S}>34.8$ ) is plotted in units of $1013 \mathrm{~m}^{3}$. Symbols are defined at Figures $3 \mathrm{a}-3 \mathrm{c}$. Horizontal lines during the 1970s and 1980s are decadal mean freshwater from $E W G$ [1997, 1998] summer and winter atlases integrated over the volume of subdomain "A". 


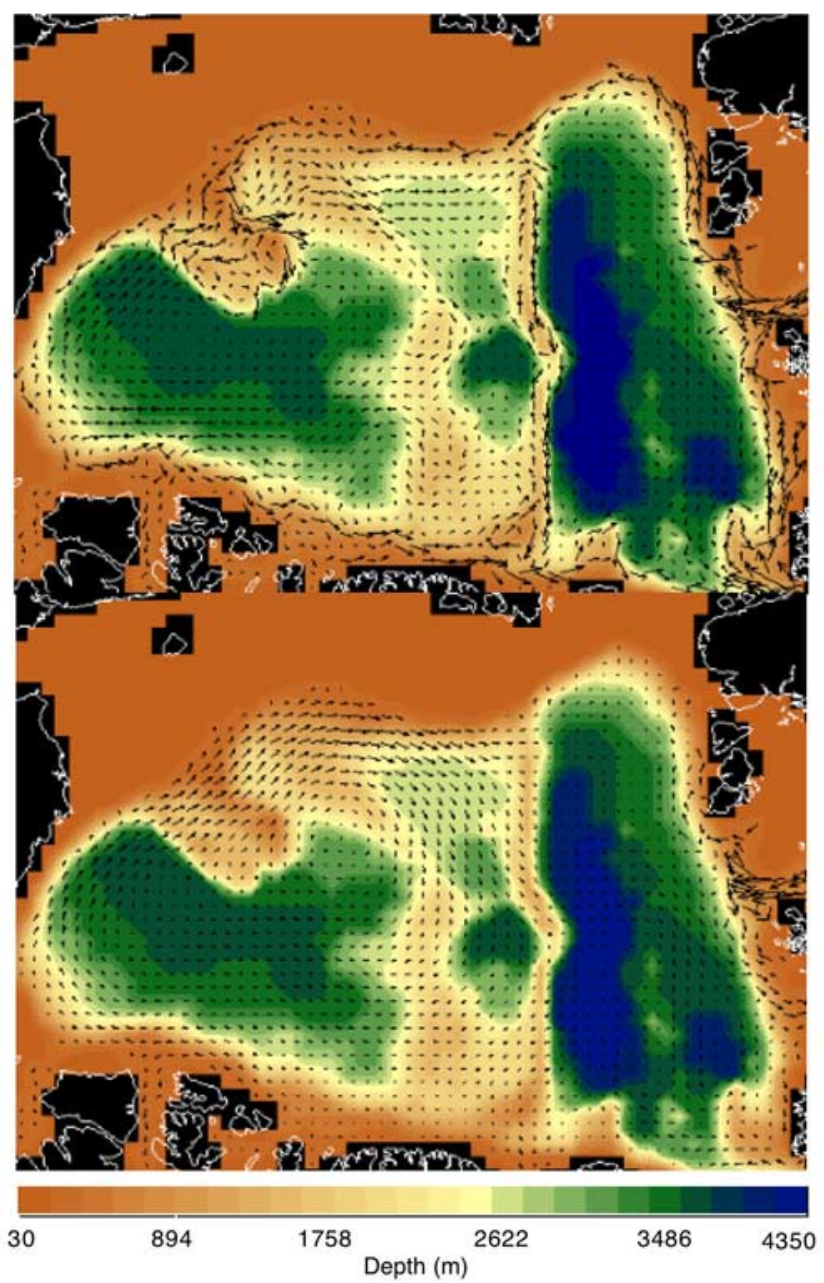

Figure 6a. Flow is shown over bathmetry during December 1987 from model 'IOS'. (top) Using neptune parameters. (bottom) Modified to replace neptune with traditional friction.

or annual intervals. For present purposes we use summer and winter compilations of $\theta$ and $\mathrm{S}$ from the $E W G[1997$, 1998], which are provided as averages by decades from 1950 s through 1980s. These decadal averages for 1970s and 1980s are included on Figures $3 \mathrm{a}$ and $3 \mathrm{~b}$ and Figures $5 \mathrm{a}$ and $5 \mathrm{~b}$. There are cautions. The number of observations included into EWG average during the 1980s is far fewer than during the 1970s. Variability within EWG is problematic, as critically examined by Polyakovet al. [2003]. Further analyses of interannual variability in Arctic subdomains are given by Swift et al. [2005]. While AOMIP models clearly show drifts, inferences from decadal averages from EWG should also be considered with caution.

[24] We extend the comparison of models with EWG in Figure 11, left panel. Plotted are the models' 1980s results with 1980s EWG, averaging summer and winter (which in all cases are nearly alike except in shallow surface layers) over the Amerasian domain. A concern, also in analyses of Karcher et al. [2007], is that most models exhibit a progressive thickening/deepening of the Atlantic Layer (often defined by $0^{\circ} \mathrm{C}$ potential temperature bounds). By making a plot from 1980s for the Amerasian domain, we are choosing the latest period for which basin average observations are available and we are looking relatively "downstream" from the Atlantic source. A concern can be raised that EWG during the 1980s uses fewer observations than during 1970s; however, an EWG plot from 1970s (not shown) was found to be nearly identical to the 1980s plot, hence the 1980s comparison in Figure 11.

[25] Figure 11 shows the wide scatter of results that has characterized nearly every AOMIP comparison to date. We observe that, except for two models which remain quite cold (without Amerasian basin Atlantic Layer as expressed by $\theta>0^{\circ} \mathrm{C}$ ), models tend to realize too-thick and too-deep Atlantic Layers. Here we gain insight from tests performed with the POL model. A concern is for quality of numerical methods for solving advection-diffusion equations for tracers such as $\theta$ and $\mathbf{S}$. It is a classical problem in numerical fluid dynamics to find methods to advect tracers without excessive diffusion (explicit or implicit) while containing spurious tracer dispersion. Among AOMIP models, schemes have included flux corrected transport (FCT) and higher order upstream, for examples. Recently, Hofmann and Morales Maqueda [2006] examined the second order moment (SOM) method of Prather [1986] while Morales Maqueda and Holloway [2006] introduced this into AOMIP

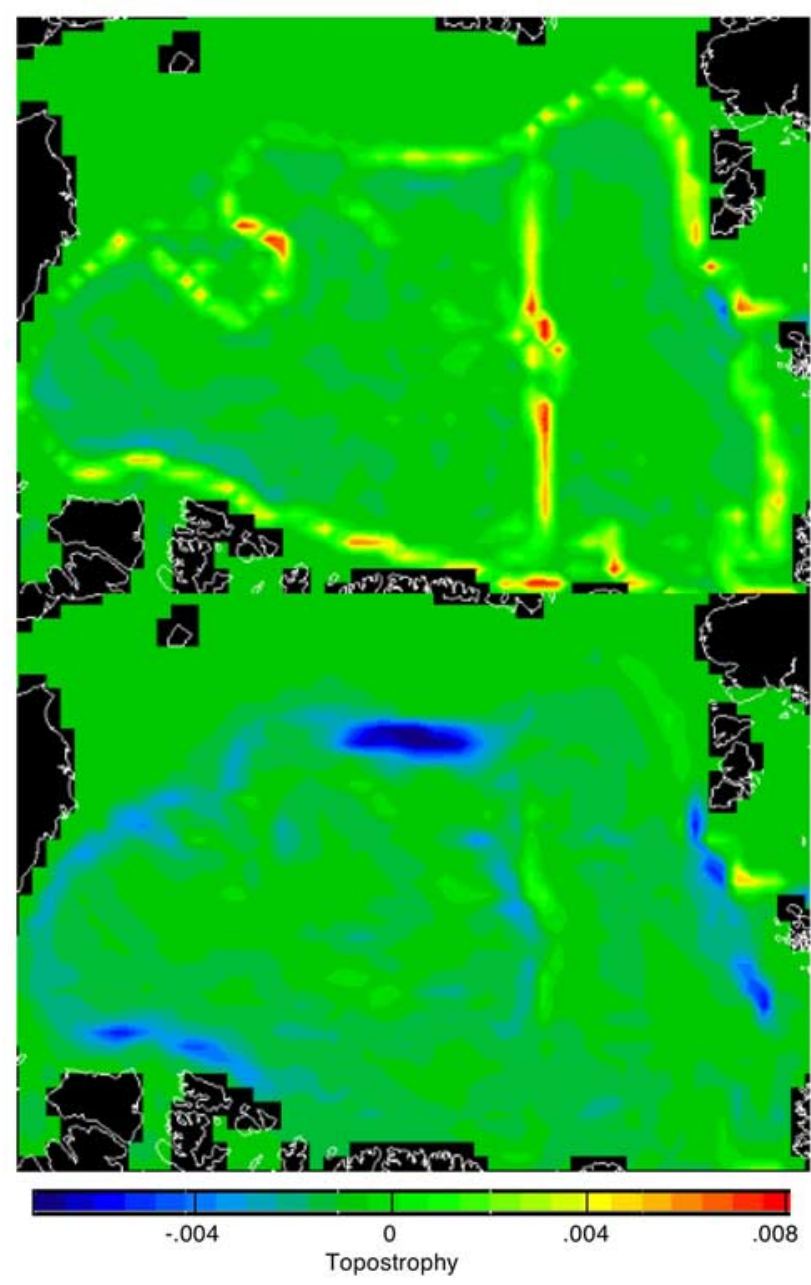

Figure 6b. Topostrophy corresponding to Figure 6a. 


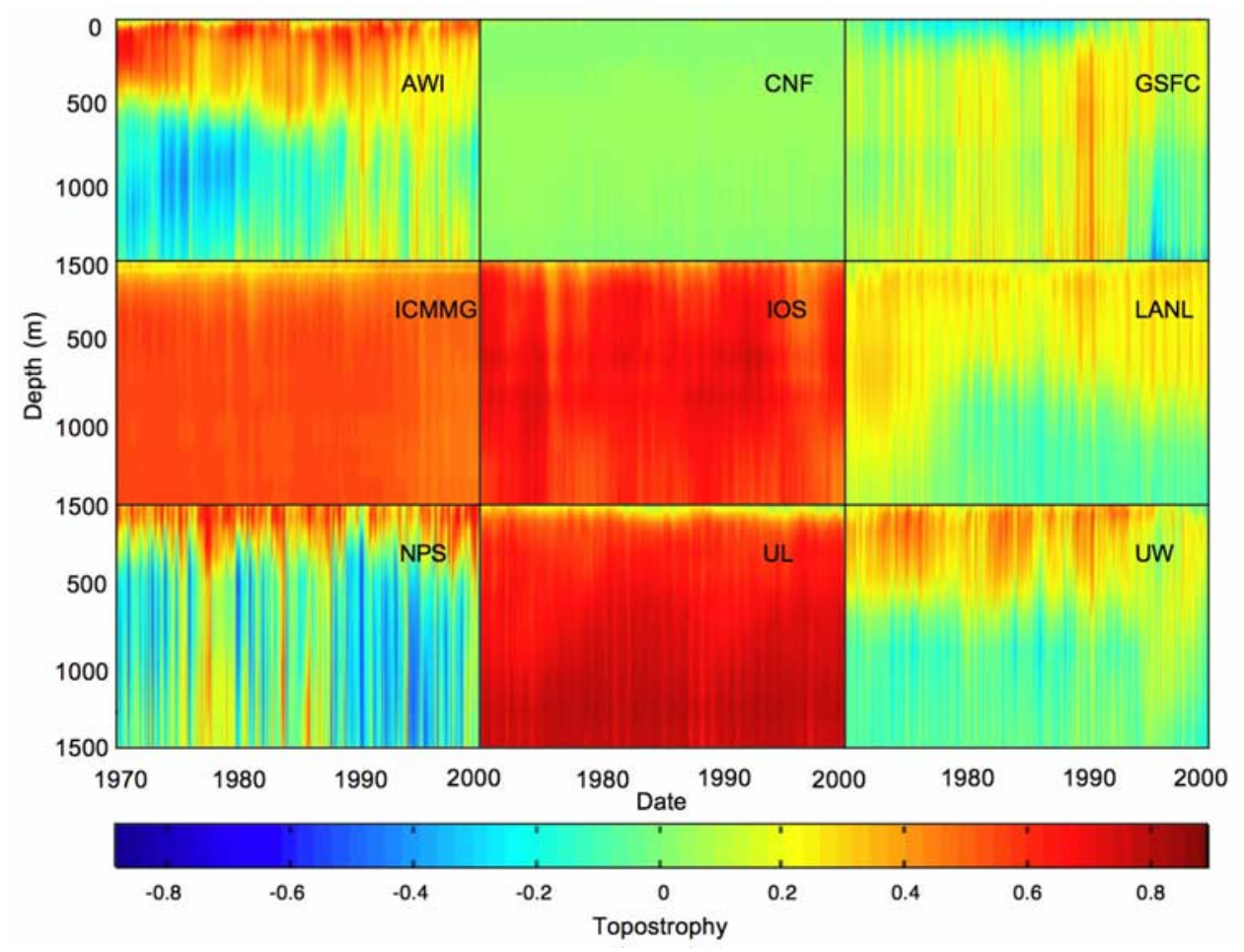

Figure 7a. Monthly mean normalized topostrophy is shown as a function of depth and time for models AWI, CNF, GSFC, ICMMG, IOS, LANL, UL, NPS and UW for subdomain "E".

modeling (IOS and POL models). Alone SOM does not fully prevent spurious dispersion, and Morales Maqueda and Holloway [2006] consider limiters denoted "A", "B" and " $\mathrm{C}$ " to prevent dispersion.
[26] The right side of Figure 11 shows results from POL with advection using FCT, SOM and SOM with "C" limiter, compared with EWG. SOM retains the sharpest Atlantic Layer core without excessive deepening. When the "C"

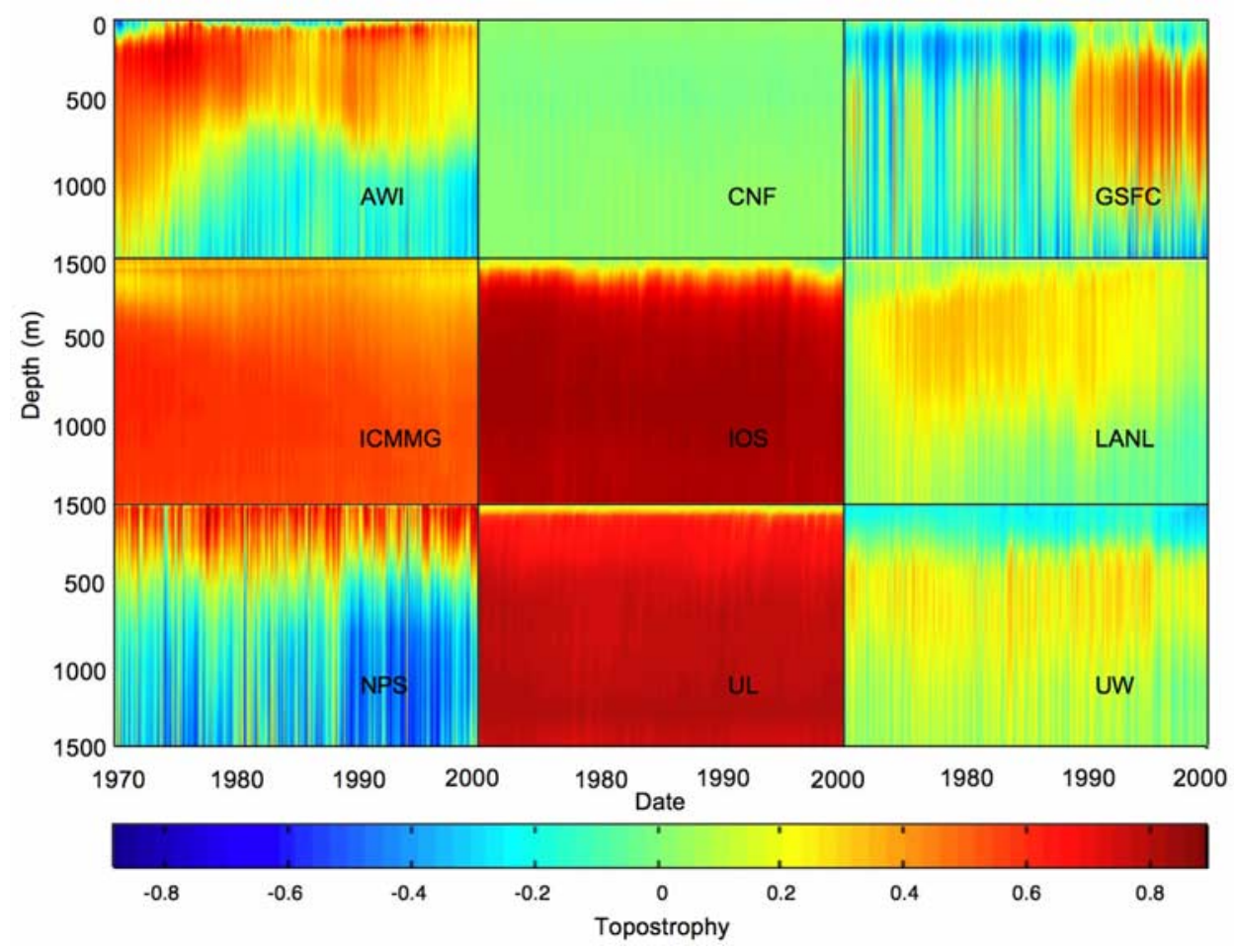

Figure 7b. Monthly mean normalized topostrophy is shown as a function of depth and time for models AWI, CNF, GSFC, ICMMG, IOS, LANL, UL, NPS and UW for subdomain "A". 
Table 3. Actual Ranges of Topostrophies for Each Model in Subdomains "E" and "A"

\begin{tabular}{|c|c|c|c|c|c|c|c|c|c|c|}
\hline & & AWI & GSFC & CNF & ICM & IOS & LANL & NPS & UL & UW \\
\hline & $\begin{array}{l}\text { "E" } \\
\text { "A" }\end{array}$ & $\begin{array}{l}-.522 \\
-.849\end{array}$ & $\begin{array}{l}-.891 \\
-.952\end{array}$ & $\begin{array}{l}-.141 \\
-.280\end{array}$ & $\begin{array}{l}.000 \\
.000\end{array}$ & $\begin{array}{l}-.043 \\
-.196\end{array}$ & $\begin{array}{l}-.180 \\
-.163\end{array}$ & $\begin{array}{l}-.597 \\
-.767\end{array}$ & $\begin{array}{l}-.192 \\
-.097\end{array}$ & $\begin{array}{l}-.470 \\
-.371\end{array}$ \\
\hline $\operatorname{Max} \tau$ & $\begin{array}{l}\text { "E" } \\
\text { "A" }\end{array}$ & $\begin{array}{l}.790 \\
.781\end{array}$ & $\begin{array}{l}.524 \\
.729\end{array}$ & $\begin{array}{l}.198 \\
.527\end{array}$ & $\begin{array}{l}.579 \\
.603\end{array}$ & $\begin{array}{l}.794 \\
.842\end{array}$ & $\begin{array}{l}.380 \\
.359\end{array}$ & $\begin{array}{l}.789 \\
.887\end{array}$ & $\begin{array}{l}.807 \\
.814\end{array}$ & $\begin{array}{l}.624 \\
.382\end{array}$ \\
\hline
\end{tabular}

limiter is applied, the result is more diffusive, eroding core temperature but without excessive deepening. FCT induces still more numerical diffusion, deepening the Atlantic Layer.

[27] A new result, not previously recognized across the AOMIP suite, is that the models are remarkably consistent about exhibiting a nearly linear thermal stratification in the upper ocean (spanning approximately 50 to $200 \mathrm{~m}$ in Figure 11). Although this agreement among AOMIP models is remarkable, observations (here from EWG) contradict the models, showing instead the more-nearly isothermal layer characteristic of a cold halocline. While results in Figure 11 are only for the Amerasian basin during the 1980s, examination of results (not shown) during the 1970s, for summer and winter separately, and for the Eurasian as well as Amerasian basins, consistently show models failures to develop realistic cold haloclines [cf. Steele and Boyd, 1998; Woodgate et al., 2001; Shimada et al., 2005]. Moreover, the POL model tests on the right of Figure 11 show the same unrealistic thermal stratification in the upper ocean, indicating this is not an artifact of numerical advection. The overall result suggests missing or misrepresented physical processes (across the AOMIP suite), perhaps involving aspects of shelf-basin exchange [Aagaard et al., 1981; Melling and Lewis, 1982] and/or perhaps involving upper ocean convective mixing [Rudels et al., 1996] in partially icecovered seas.

\subsection{Circulation}

[28] Differences seen among model outputs for $\theta$ and $\mathrm{S}$ are even more striking when viewing circulation diagnostics such as topostrophy, $\tau$, and speed. Because of limited direct observation of velocity, e.g. to construct basin averaged $\tau$, present discussion will concern only differences among models.

[29] Our main indicator of circulation is $\tau$, as described and illustrated at Figures $6 \mathrm{a}$ and $6 \mathrm{~b}$. (See also application of topostrophy by Merryfield and Scott [2007] diagnosing global ocean models.) Most AOMIP models, as seen in Figures $7 \mathrm{a}$ and $7 \mathrm{~b}$, show highly variable $\tau$, of either sign and readily sign-reversible about small (normalized) values with basin averages typically $|\tau|<0.3$ (see Figures 8a and $8 \mathrm{~b}$ ). Such weak, ambivalent, sign-reversible $\mathrm{t}$ is consistent with previous remarks [e.g., Proshutinsky et al., 2005] that some models obtain cyclonic, others anticyclonic, flow where "cyclonic" and "anticyclonic" are based on visual impression of models' vector flow fields.

[30] Weak, ambivalent, sign-reversible $\tau$ may be consistent with the analysis of Yang [2005] who argues from an idealized potential vorticity budget that even slight changes to forcing on open lateral boundaries of the Arctic can yield reversible circulations. Karcher et al. [2007] compared models AWI, LANL and UW to confirm a link between lateral PV flux and AW layer circulation intensity, finding also significant influence of local and remote wind field variability on the AW layer circulation. Zhang and Steele [2007] show that AW circulation in the UW model is sensitive to the coefficient for vertical tracer diffusion. Sensitivity is further supported by Hunke and Holland [2007] who find that relatively minor changes in surface forcing of the LANL model significantly influence modeled AW circulation.

[31] A much larger and persistent difference among models is seen in Figures 7a and 7b and Figures $8 \mathrm{a}$ and $8 \mathrm{~b}$ where three models (ICMMG, IOS and UL) are set apart

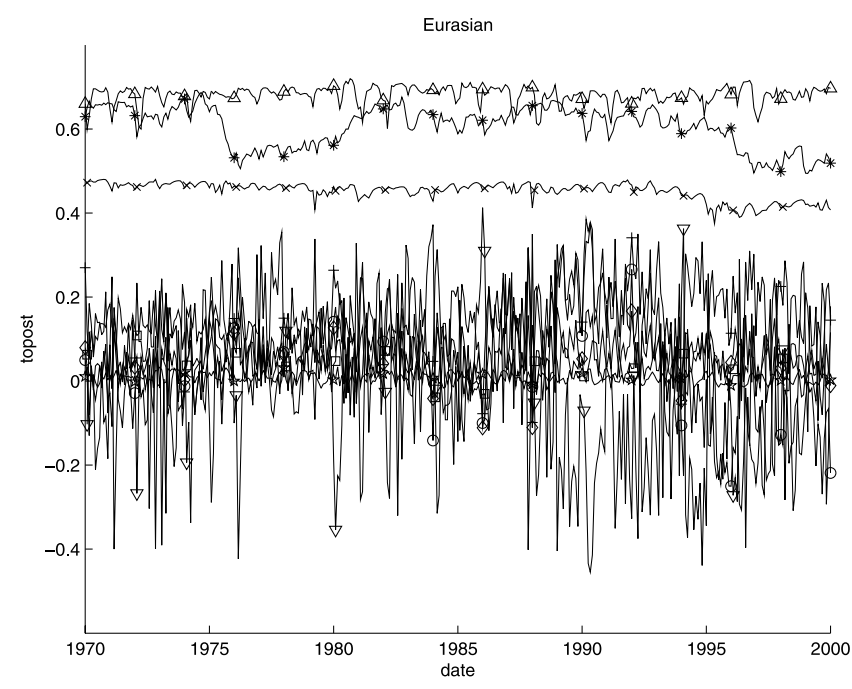

Figure 8a. Normalized topostrophy (dimensionless) is plotted with symbols defined at Figures $3 a-3 c$ averaged over the volume of subdomain "E".

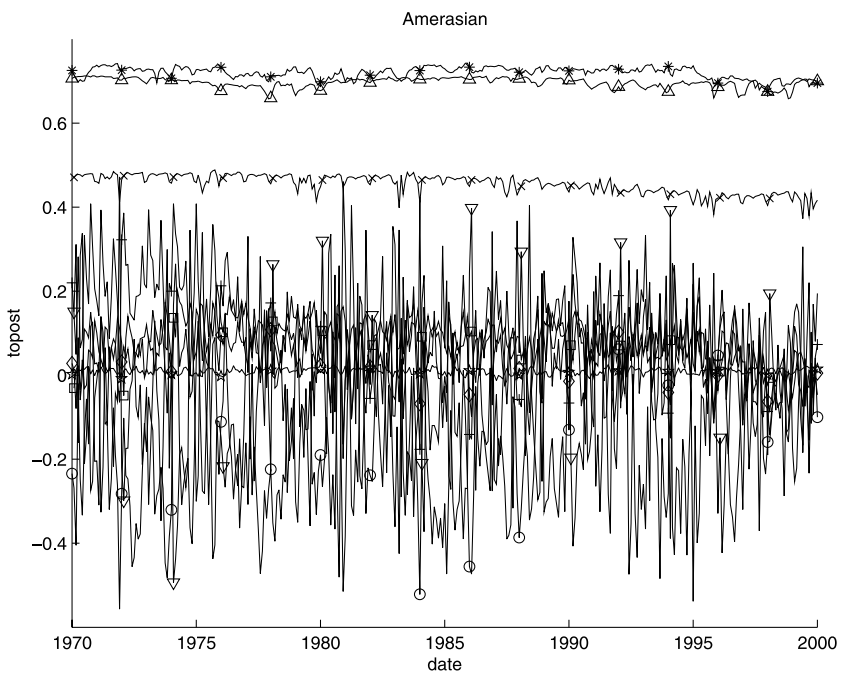

Figure $\mathbf{8 b}$. Normalized topostrophy (dimensionless) is plotted with symbols defined at Figures $3 a-3 c$ averaged over the volume of subdomain "A". 


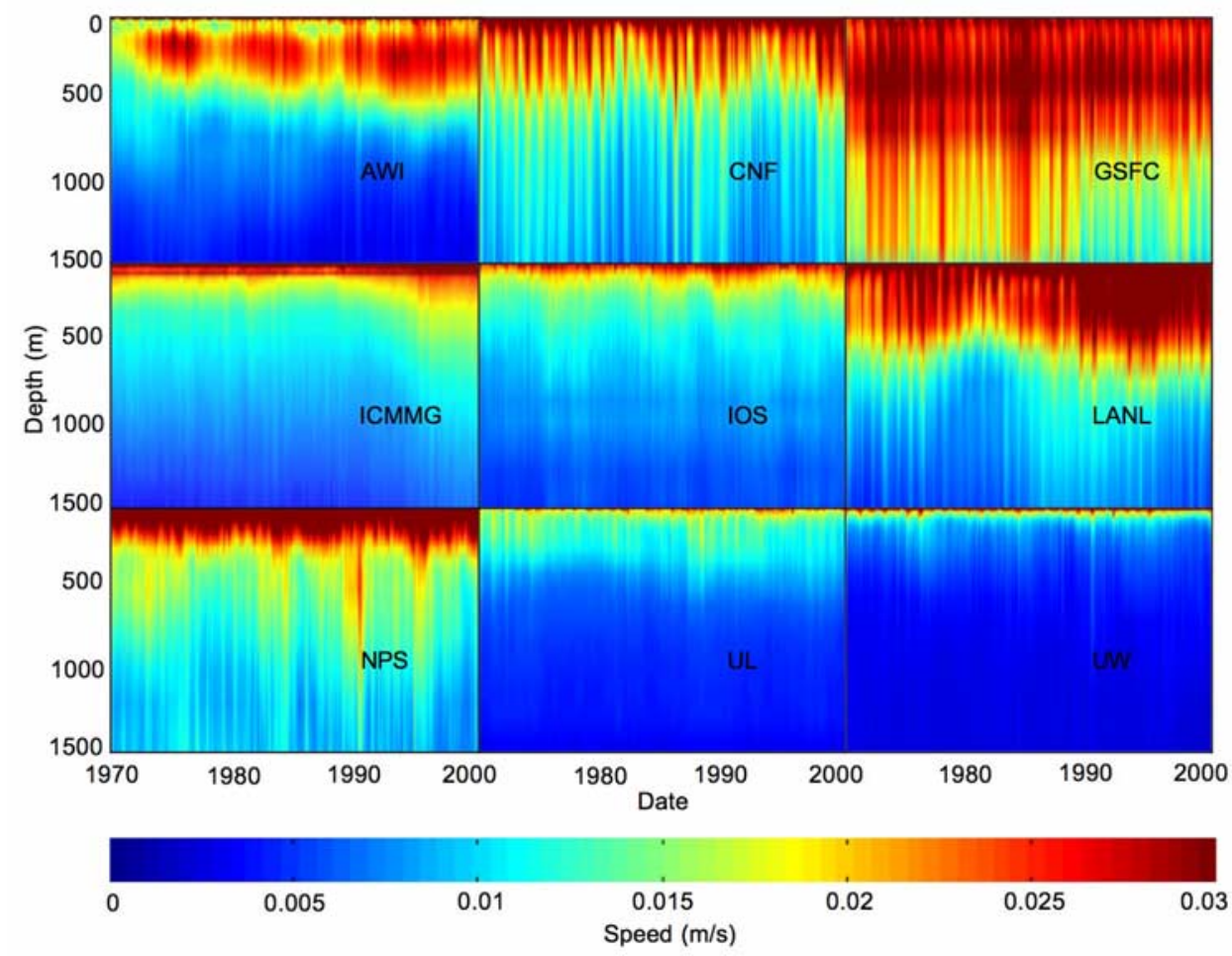

Figure 9a. Speed of monthly mean flow is shown as a function of depth and time for models AWI, CNF, GSFC, ICMMG, IOS, LANL, UL, NPS and UW averaged over subdomain "E".

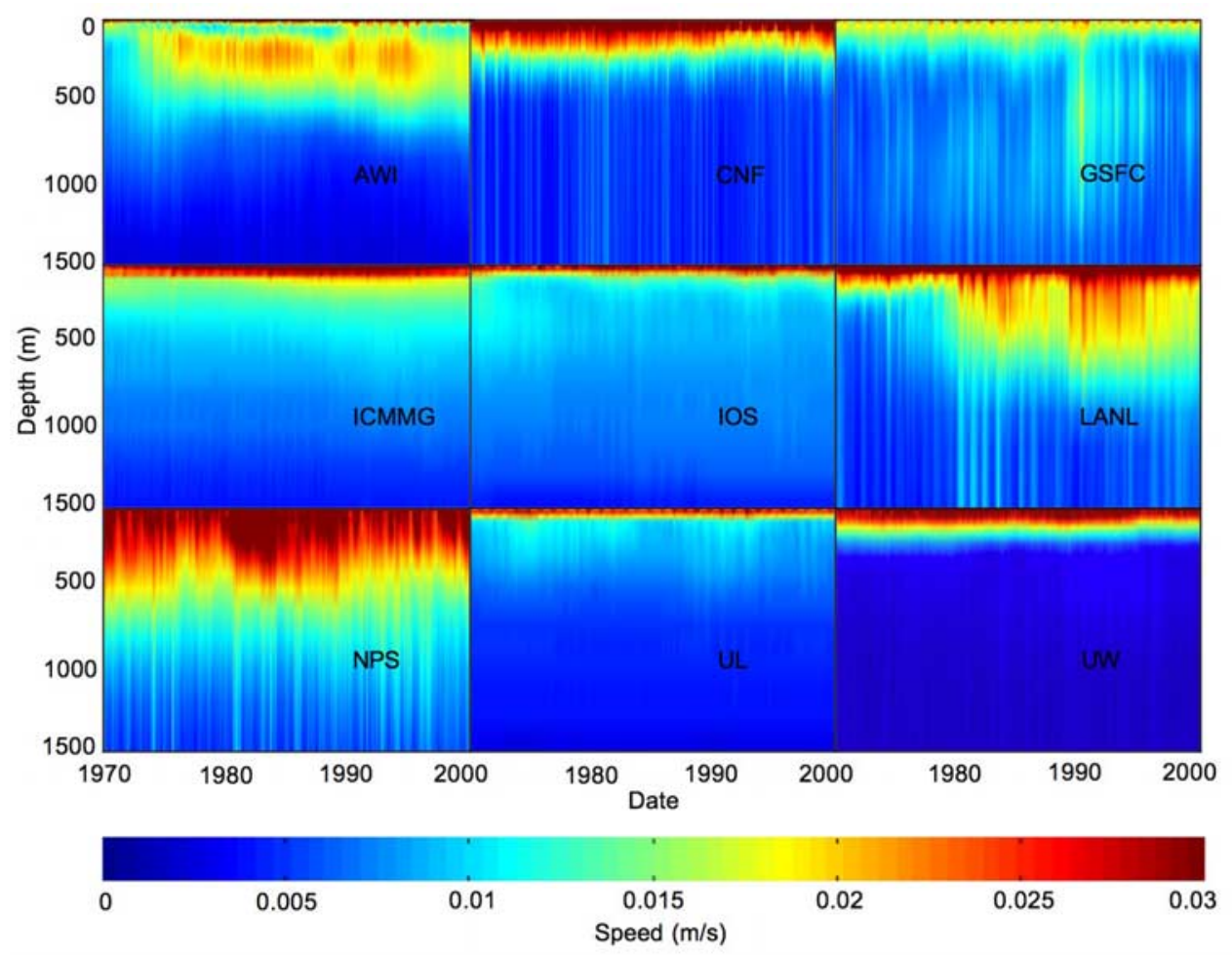

Figure 9b. Speed of monthly mean flow is shown as a function of depth and time for models AWI, CNF, GSFC, ICMMG, IOS, LANL, UL, NPS and UW averaged over subdomain "A”. 
Table 4. Maxima of Speed $(\mathrm{m} / \mathrm{s})$ for Each Model in Subdomains "E" and "A"

\begin{tabular}{lccccccccc}
\hline & AWI & GSFC & CNF & ICM & IOS & LANL & NPS & UL & UW \\
\hline "E" & .105 & .066 & .078 & .056 & .089 & .085 & .111 & .043 & .083 \\
"A" & .076 & .056 & .082 & .046 & .078 & .080 & .083 & .047 & .070 \\
\hline
\end{tabular}

from the other six models. Model POL (not shown) is similar to IOS (shown). In Figures $8 \mathrm{a}$ and $8 \mathrm{~b}$, effort was not made to disentangle the several traces clustered about small $|\tau|$, e.g. by isolating a subsets of models as Karcher et al. [2007]. Instead, the key observation is that the set of models with small, variable $\tau$ are nearly disjoint from the set of models with large, persistent $\tau$. We can test why the high- $\tau$ models differ from the others. It is due to physics parameterization, following "neptune" [Nazarenko et al., 1998; Polyakov, 2001; Holloway, 2004] which has unresolved subgrid eddies acting to force mean flow. The small $|\tau|$ AOMIP models assume that unresolved subgrid eddies act as friction (under harmonic or biharmonic operators), resisting mean flow. A simple test was made by changing the IOS model from neptune to friction with a sample from that test shown in Figures $6 \mathrm{a}$ and $6 \mathrm{~b}$. The result is consistent with previous results of Nazarenko et al. [1998] or Polyakov [2001].

[32] The difference between frictional and neptune models is large. Not only is $\tau$ larger with neptune but also the striking sensitivity of frictional Arctic models - to details of forcing, to open boundary conditions or to internal mixing coefficients - is much suppressed. However, at the present stage in AOMIP and given the paucity of direct velocity measurements in the Arctic, we only take note of these differences without attempting to assess whether friction or neptune is more realistic.

\section{Summary}

[33] A first goal for AOMIP has been to identify key differences among Arctic models' outputs under conditions

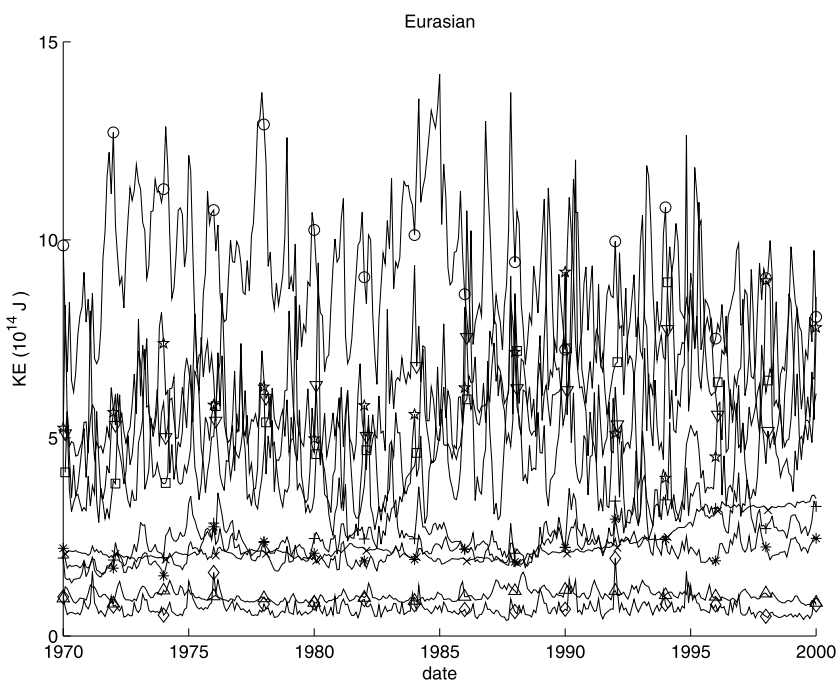

Figure 10a. Total kinetic energy of monthly mean flows is plotted in units of $1014 \mathrm{~J}$ integrated over the volume of subdomain "E". Symbols are defined at Figures 3a-3c. where initialization and forcing are as nearly common as possible. The present paper represents a step in this process as we examine results from ten of the AOMIP models, each forced from 1948 through 2000 (or beyond). We consider ocean variables: temperature, salinity and velocity. Sea ice variables are considered by Johnson et al. [2007] and Martin and Gerdes [2007].

[34] A challenge is to develop diagnostics that permit meaningful intercomparison given the overwhelming size of models' outputs (up to $\mathrm{O}\left(10^{11}\right)$ values from each model). We proceed by examining monthly averaged outputs laterally integrated over two subdomains: the Amerasian and Eurasian basins (Figure 1), retaining dependence on depth. To assure comparable integrations, subdomain boundaries are precisely defined. After integrations are intialized from 1948, we compare over a 30-year analysis period 1970 through 1999.

[35] Potential temperature, $\theta$, and salinity, $\mathrm{S}$, are straightforward to compare in terms of their lateral averages and in terms of total heat (referenced to $0^{\circ} \mathrm{C}$ ) and freshwater (referenced to 34.8 PSU) storage. It is surprising and not yet understood how large the differences are among models (Figures $2 \mathrm{a}$ and $2 \mathrm{~b}, 3 \mathrm{a}$ and $3 \mathrm{~b}, 4 \mathrm{a}$ and $4 \mathrm{~b}$, and $5 \mathrm{a}$ and $5 \mathrm{~b}$ ) despite efforts across AOMIP toward common initialization and forcing. Comparison with observations is provided by plotting decadal averages from the summer and winter $E W G$ [1997, 1998] atlases onto 3a and 3b and 5a and 5b. Differences among models outputs are due, in part, to thermal and freshwater anomalies imported to the Arctic from lower latitudes. Differences are also due to physics, parameters and numerical methods expressed within the Arctic.

[36] We begin to identify systematic deficiencies common to many or most AOMIP models. It is seen that the Atlantic Layer (defined by $\theta>0{ }^{\circ} \mathrm{C}$ ) tends to become too thick, extending too deep in comparison with EWG (Figure 11). This is shown to depend, in part, upon the quality of numerical advection, which can require excessive diffusion (explicit or implicit) to prevent spurious dispersion. Advanced numerical methods, e.g., second order moment advection [Prather,

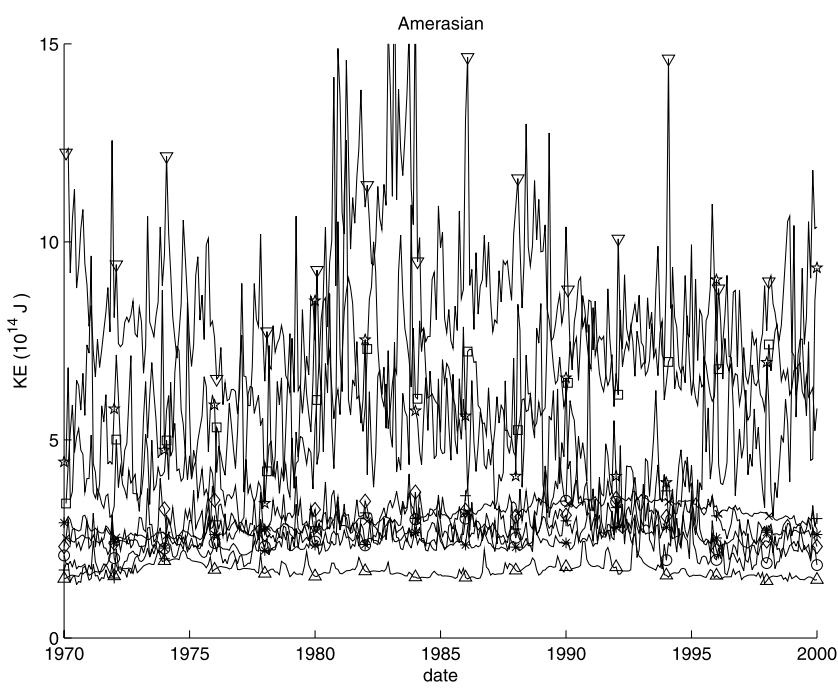

Figure 10b. Total kinetic energy of monthly mean flows is plotted in units of $1014 \mathrm{~J}$ integrated over the volume of subdomain "A". Symbols are defined at Figures 3a-3c. 


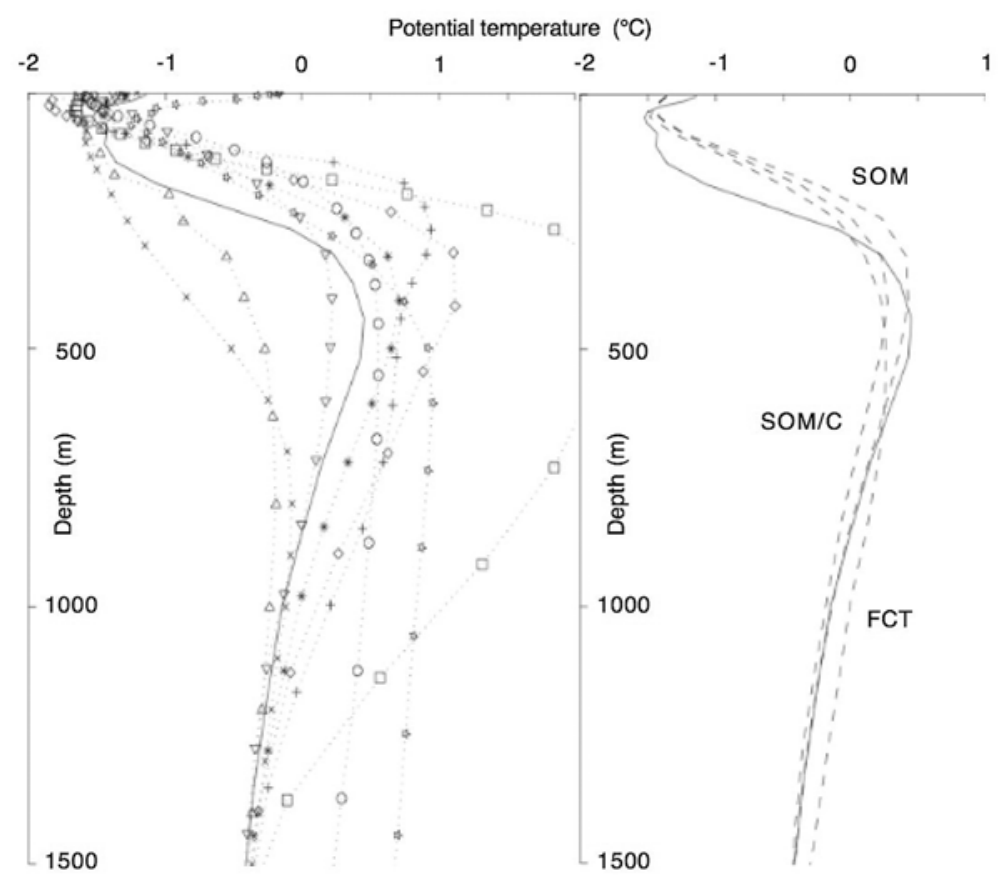

Figure 11. (left) Averages of models' summer (July, August, September) and winter (March, April, May) temperatures, averaged from 1980 through 1989, are compared with the average of EWG summer and winter atlases (solid trace), 1980s decadal mean. Symbols are defined at Figures 3a-3c. All variables are averaged over the Amerasian domain. (right) Dashed curves are from the POL model using second order moment advection without limiters (SOM), SOM advection with " $\mathrm{C}$ " limiter (SOM/C), and with FCT advection, averaged as on left panel. The solid curve is EWG from the left panel.

1986], can limit over-deepening (Figure 11). It is further seen, viz. Holloway and Proshutinsky [2007], that the suite of AOMIP models tend to show systematic growth of ocean heat over the entire AOMIP period 1950 to 2000, contrary to decadal averages from EWG over 1950 to 1990 . The role of tides, which are absent from AOMIP models except IOS, is shown to be effective at ventilating Atlantic heat, reducing excessive growth of heat.

[37] Figure 11 reveals also that AOMIP models characteristically tend toward uniformly thermally stratified upper ocean (below a seasonal mixed layer), contrary to observations of a more nearly isothermal "cold halocline" upper ocean. This systematic discrepancy was not previously realized and is not yet explained, suggesting instead that fundamental Arctic processes may be missing or misrepresented, perhaps associated with convective mixing under partial ice cover or with shelf-basin exchanges.

[38] Diagnosing models' circulation characteristics poses a different challenge insofar as lateral averages of vector fields can be meaningless while raw maps of flow vectors, considered at all depths at all times, are overwhelming. We introduce topostrophy, $\tau$, the upwards component of $\mathbf{V} \times \nabla \mathrm{D}$ where $\mathbf{V}$ is monthly mean velocity and $\nabla \mathrm{D}$ is the gradient of total depth. As seen in Figures $6 \mathrm{a}$ and $6 \mathrm{~b}$, positive $\tau$ expresses the idea that northern hemisphere flows tend to keep shallow water to the right. Thus $\tau$ is a scalar field that can be averaged just as $\theta$ and S. In the Arctic, positive $\tau$ characterizes cyclonic "rim currents".

[39] Averaged $\tau$ differs markedly among AOMIP models, separating the AOMIP suite into two groups. Four models
(ICMMG, IOS, POL, UL) show large, positive, persistent $\tau$ while the other six models show $\tau$ with small amplitude, ambivalent sign, and high temporal variability. In this case we find certainly that the difference between models with large, positive $\tau$ and those with small, ambivalent $\tau$ is due to models' assumptions about the role of unresolved subgridscale eddies. Traditional assumptions that subgrid eddies act frictionally, damping mean flows, yield the results with small ambivalent $\tau$. Statistical theory ("neptune") that eddies act to force mean flows [Nazarenko et al., 1998; Polyakov, 2001; Holloway, 2004] yield the results with large persistent $\tau$. It is not known whether friction or neptune is more realistic.

[40] Models exhibiting small $\tau$ also differ markedly among themselves, and three of these models (AWI, LANL, UW) have been examined in more detail by Karcher et al. [2007] following a potential vorticity analysis by Yang [2005]. Further, Zhang and Steele [2007] show sensitivity of circulation to vertical mixing coefficient.

[41] As AOMIP progresses, we are increasingly able to recognize important differences among models and, where possible, differences from observations. New diagnostics such as topostrophy aid this process. We begin to recognize systematic differences and, in some cases, suggestions (quality of numerical advection, inclusion of tides) that may improve future modeling. We reveal a systematic deficiency in models' representation of upper ocean thermal stratification. This failure to form the "cold halocline" is not explained and suggests missing or misrepresented physics across the suite of AOMIP modeling. We find 
Table A1. Vertical Coordinates

\begin{tabular}{llccc}
\hline & \multicolumn{1}{c}{ Type } & Number of Levels & Min Spacing & Max Spacing \\
\hline AWI & Z & 33 & $10 \mathrm{~m}$ & $356 \mathrm{~m}$ \\
CNF & sigma-z hybrid & 47 & $2.5 \mathrm{~m}$ & $250 \mathrm{~m}$ \\
GSFC & Sigma & 20 & 0.00125 sigma & 0.2 sigma \\
ICMMG & Z & 33 & $10 \mathrm{~m}$ & $500 \mathrm{~m}$ \\
IOS & $\mathrm{Z}$ & 29 & $10 \mathrm{~m}$ & $290 \mathrm{~m}$ \\
LANL & $\mathrm{Z}$ & 40 & $10 \mathrm{~m}$ & $250 \mathrm{~m}$ \\
NPS & Z & 30 & $20 \mathrm{~m}$ & $200 \mathrm{~m}$ \\
POL & Z & 26 & $5 \mathrm{~m}$ & $500 \mathrm{~m}$ \\
UL & Z & 29 & $10 \mathrm{~m}$ & $290 \mathrm{~m}$ \\
UW & Z & 25 & $10 \mathrm{~m}$ & $790 \mathrm{~m}$ \\
\hline
\end{tabular}

Table A2. Horizontal Coordinates

\begin{tabular}{llllll}
\hline & \multicolumn{1}{c}{ Type } & Number of Nodes & Min Spacing & Max Spacing & \multicolumn{1}{c}{ Domain } \\
\hline AWI & B, rotated spherical & 41310 & $25.8 \mathrm{~km}$ & $27.8 \mathrm{~km}$ & $50 \mathrm{~N}$ Atl to Bering Str \\
CNF & B, rotated spherical & $1280 \times 912$ & $.28^{\circ} \times .19^{\circ}$ & $25 \mathrm{~km}$ & global \\
GSFC & C, rotated spherical & $150 \times 142$ & $0.7^{\circ}$ & $0.9^{\circ}$ & 16S Atl to Bering Str \\
ICMMG & spherical+bipolar & $140 \times 180$ & $35 \mathrm{~km}$ & $1^{\circ}$ & Atl. + Arctic \\
IOS & B, rotated spherical & $91 \times 67$ & $0.5^{\circ}$ & $0.5^{\circ}$ & GINS to Bering Str \\
LANL & B, general curvilinear & $900 \times 600$ & $9 \mathrm{~km}$ & $44 \mathrm{~km}$ & global \\
NPS & B, rotated spherical & $384 \times 304$ & $1 / 6^{\circ}$ & $18.5 \mathrm{~km}$ & $50 \mathrm{~N}$ Atl to Bering Str \\
POL & B, rotated spherical & $120 \times 129$ & $30 \mathrm{~km}$ & $300 \mathrm{~km}$ & global \\
UL & B, rotated spherical & $105 \times 112$ & $0.5^{\circ}$ & $0.5^{\circ}$ & $50 \mathrm{~N}$ Atl to Bering Str \\
UW & B, general curvilinear & $130 \times 102$ & $\sim 40 \mathrm{~km}$ & $\sim 40 \mathrm{~km}$ & Arctic + GINS + Baffin \\
\hline
\end{tabular}

Table A3. Open Boundaries

\begin{tabular}{llll}
\hline & \multicolumn{1}{c}{ Locations } & \multicolumn{1}{c}{ Condition } & \multicolumn{1}{c}{ Transports, Sv } \\
\hline AWI & N Atlantic only & radiation & none \\
CNF & Global & n/a & n/a \\
GSFC & Bering, S Atlantic & radiation & Bering 0.8 in \\
ICMMG & Bering, Atlantic & Neumann & Bering 0.8 in \\
IOS & Bering, Baffin Bay, GINSea & Dirchlet + Neumann & Bering 0.8 in, Baffin 1.0 out, GINS 0.2 in \\
LANL & Global & n/a & n/a \\
NPS & all closed + restoring & restoring & none \\
POL & Global & n/a & n/a \\
UL & Bering, N Atlantic & Dirchlet + Neumann & Bering 1.0 in \\
UW & Bering, Davis, Denmark, Faero-Shetland & Zhang and Steele $[2007]$ & Bering 0.8 in, Atlantic 0.8 out \\
\hline
\end{tabular}

Table A4. Bottom Topography

\begin{tabular}{|c|c|c|c|c|}
\hline & Source & Modifications & Min Depth & Max Depth \\
\hline AWI & IBCAO & deepened some channels & $30 \mathrm{~m}$ & $4800 \mathrm{~m}$ \\
\hline $\mathrm{CNF}$ & ETOPO2 & high lat. smoothing & $10 \mathrm{~m}$ & $4948 \mathrm{~m}$ \\
\hline GSFC & TerrainBase Global DTM & extensive smoothing & $50 \mathrm{~m}$ & $6000 \mathrm{~m}$ \\
\hline ICMMG & IBCAO & deepened some channels & $50 \mathrm{~m}$ & $5500 \mathrm{~m}$ \\
\hline IOS & IBCAO + ETOPO5 & widened Nares Strait & $30 \mathrm{~m}$ & $4345 \mathrm{~m}$ \\
\hline LANL & IBCAO + Smith and Sandwell & pointwise changes & $20 \mathrm{~m}$ & $5500 \mathrm{~m}$ \\
\hline NPS & $\mathrm{IBCAO}+$ ETOPO5 & widened some straits & $45 \mathrm{~m}$ & $4300 \mathrm{~m}$ \\
\hline POL & IBCAO + ETOPO5 & some & $15 \mathrm{~m}$ & $5500 \mathrm{~m}$ \\
\hline UL & IBCAO + ETOPO5 & widened some straits & $30 \mathrm{~m}$ & $4345 \mathrm{~m}$ \\
\hline UW & IBCAO + ETOPO5 & & $50 \mathrm{~m}$ & $5376 \mathrm{~m}$ \\
\hline
\end{tabular}

Table A5. Statistics of Basin Geometries

\begin{tabular}{|c|c|c|c|c|c|c|c|c|c|c|}
\hline & & AWI & $\mathrm{CNF}$ & GSFC & ICMMG & IOS & LANL & NPS & UL & UW \\
\hline \multirow[t]{3}{*}{ Amerasian } & Surface area, $10^{12} \mathrm{~m}^{2}$ & 4.7 & 5.56 & 5.07 & 4.62 & 5.14 & 4.93 & 5.22 & 5.36 & 4.96 \\
\hline & Volume, $10^{15} \mathrm{~m}^{3}$ & 6.22 & 8.09 & 6.13 & 7.01 & 7.35 & 7.26 & 7.36 & 7.38 & 7.98 \\
\hline & R.m.s. slope, $10^{-3}$ & 7.1 & 11.8 & 3.8 & 13.9 & 7.6 & 15.4 & 6.9 & 7.0 & 11.7 \\
\hline \multirow[t]{3}{*}{ Eurasian } & Surface area, $10^{12} \mathrm{~m}^{2}$ & 2.34 & 2.57 & 2.61 & 2.38 & 2.59 & 2.45 & 2.56 & 2.57 & 2.42 \\
\hline & Volume, $10^{15} \mathrm{~m}^{3}$ & 4.47 & 5.81 & 3.9 & 4.99 & 5.45 & 5.2 & 5.35 & 5.34 & 5.84 \\
\hline & R.m.s. slope, $10^{-3}$ & 10.4 & 14.7 & 5.2 & 18.4 & 9.1 & 19.1 & 9.9 & 11.0 & 15.2 \\
\hline
\end{tabular}


Table A6. Friction

\begin{tabular}{|c|c|c|c|}
\hline & Vertical & Horizontal & Bottom \\
\hline AWI & constant, $10 \mathrm{~cm}^{2} / \mathrm{s}$ & biharmonic, A $4=0.5 \mathrm{e}-21 \mathrm{~cm}^{4} / \mathrm{s}$ & quadratic, $1.2 \mathrm{e}-3$ \\
\hline CNF & MY2.5 & Smagorinsky biharmonic & Rayleigh-Coriolis above $2000 \mathrm{~m}$ \\
\hline GSFC & MellorYamada2.5+5e6 & Smagorinsky & quadratic \\
\hline ICMMG & constant, $10 \mathrm{~cm}^{2} / \mathrm{s}$ & neptune, $\mathrm{L}=3.5 \mathrm{e} 3 \mathrm{~m}, \mathrm{~A} 2=2 \mathrm{e} 4 \mathrm{~m}^{2} / \mathrm{s}$ & quadratic, $2 \mathrm{e}-3$ \\
\hline IOS & neptune, $.05 \mathrm{~m}^{2} / \mathrm{s}$ & neptune, $\mathrm{L}=3.5 \mathrm{e} 3 \mathrm{~m}, \mathrm{~A} 2=3 \mathrm{e} 4 \mathrm{~m}^{2} / \mathrm{s}$ & quadratic, $1.2 \mathrm{e}-3$ \\
\hline LANL & $10 \times$ tracer $\mathrm{KPP}$ & biharmonic, $\mathrm{A} 4=1 . \mathrm{e} 20 \mathrm{~cm}^{4} / \mathrm{s}$ & quadratic, $1.22 \mathrm{e}-3$ \\
\hline NPS & Pacanowski and Philander & biharmonic, A4 = 1.e-19 $\mathrm{cm}^{4} / \mathrm{s}$ & quadratic, $1.22 \mathrm{e}-3$ \\
\hline POL & $\mathrm{KPP}+10 \mathrm{~cm}^{2} / \mathrm{s}$ & neptune/Smagorinsky & none \\
\hline UL & neptune, $.03 \mathrm{~m}^{2} / \mathrm{s}$ & neptune, $\mathrm{L}=3.5 \mathrm{e} 3 \mathrm{~m}, \mathrm{~A} 2=5 \mathrm{e} 4 \mathrm{~m}^{2} / \mathrm{s}$ & quadratic, $1.2 \mathrm{e}-3$ \\
\hline UW & $0.05 \mathrm{~cm}^{2} / \mathrm{s}$ & laplacian, $\mathrm{A} 2=1.2 \mathrm{e} 8 \mathrm{~cm}^{2} / \mathrm{s}$ & quadratic, $1.225 \mathrm{e}-3$ \\
\hline
\end{tabular}

Table A7. Mixing

\begin{tabular}{|c|c|c|c|}
\hline & Vertical & Lateral & Convection \\
\hline AWI & none (see advection) & none (see advection) & complete \\
\hline CNF & MY2.5 & Gent-McWilliams, $700 \mathrm{~m}^{2} / \mathrm{s}$ & complete \\
\hline GSFC & MellorYamada2.5+5e 6 & none & MellorYamada2.5 \\
\hline ICMMG & Bryan and Lewis [1979] $0.3-1.3 \mathrm{~cm}^{2} / \mathrm{s}$ & laplacian, 1000 to $500 \mathrm{~m}^{2} / \mathrm{s}$ & based on Richardson number \\
\hline IOS & internal wave and double diffusion & none (see advection) & complete \\
\hline LANL & KPP, no double diffusion & isopycnal-GM, $\mathrm{K}=2400 \mathrm{~m}^{2} / \mathrm{s}$ & high diff., $0.1 \mathrm{~m}^{2} / \mathrm{s}$ \\
\hline NPS & Pacanowski and Philander & biharmonic, $4 \mathrm{e} 10 \mathrm{~m}^{4} / \mathrm{s}$ & Semtner $[1974]$ \\
\hline POL & KPP + Gargett and Holloway [1984] & isopycnal-GM & complete \\
\hline UL & as IOS & laplacian, $5 \mathrm{~m}^{2} / \mathrm{s}$ & complete \\
\hline UW & constant, $0.05 \mathrm{~cm}^{2} / \mathrm{s}$ & laplacian, $4 \mathrm{~m}^{2} / \mathrm{s}$ & high diff., $.05 \mathrm{~m}^{2} / \mathrm{s}$ \\
\hline
\end{tabular}

Table A8. Advection Methods

\begin{tabular}{|c|c|c|c|}
\hline & Ocean Tracers & Ocean Momentum & Sea Ice and Snow \\
\hline AWI & FCT & centered difference & corrected upstream \\
\hline $\mathrm{CNF}$ & Leonard et al. [1993] & Ishizaki and Motoi [1999] & weighted upstream \\
\hline GSFC & Lin et al. [1994] & centered difference & centered difference \\
\hline ICMMG & linear FE & upstream viscosity & upstream + remap \\
\hline IOS & modified Prather [1986] & centered difference & modified Prather [1986] \\
\hline LANL & 3rd order upwind & centered difference & Lipscomb and Hunke [2004] \\
\hline POL & modified Prather [1986] & centered difference & modified Prather [1986] \\
\hline NPS & centered difference & centered difference & centered difference \\
\hline UL & FCT & centered difference & modified Prather SOM \\
\hline UW & centered difference & centered difference & centered difference \\
\hline
\end{tabular}

Table A9. Time Step

\begin{tabular}{|c|c|c|c|c|}
\hline & Type $^{\mathrm{a}}$ & Ocean Momentum Dt & Ocean Tracer Dt & Sea Ice Dt \\
\hline AWI & LF & $900 \mathrm{~s}$ & $900 \mathrm{~s}$ & $900 \mathrm{~s}$ \\
\hline $\mathrm{CNF}$ & $\mathrm{LF}+\mathrm{EB}+\mathrm{EF}$ & $180 \mathrm{~s} / 3 \mathrm{~s}$ & $180 \mathrm{~s}$ & $3 \mathrm{~s}$ \\
\hline GSFC & LF split & $1080 \mathrm{~s} / 60 \mathrm{~s}$ & $1080 \mathrm{~s}$ & $1080 \mathrm{~s}$ \\
\hline ICMMG & Split & $14400 \mathrm{~s}$ & $14400 \mathrm{~s}$ & $10800 \mathrm{~s}$ \\
\hline IOS & $\mathrm{LF}+\mathrm{EF}+\mathrm{PC}$ & $43200 \mathrm{~s}^{\mathrm{b}}$ & $43200 \mathrm{~s}$ & $43200 \mathrm{~s}$ \\
\hline LANL & $\mathrm{LF}+\mathrm{EF}$ & $1800 \mathrm{~s}$ & $1800 \mathrm{~s}$ & $1800 \mathrm{~s}$ \\
\hline NPS & $\mathrm{LF}+\mathrm{EF}$ & $1200 \mathrm{~s}$ & $1200 \mathrm{~s}$ & $7200 \mathrm{~s}$ \\
\hline POL & $\mathrm{LF}+\mathrm{EE}+\mathrm{IE}$ & $1440 \mathrm{~s} / 239 \mathrm{~s}$ & $43200 \mathrm{~s}$ & $43200 \mathrm{~s}$ \\
\hline UL & $\mathrm{LF}+\mathrm{PC}+\mathrm{F}$ & $21600 \mathrm{~s}^{\mathrm{b}}$ & $21600 \mathrm{~s}$ & $21600 \mathrm{~s}$ \\
\hline UW & $\mathrm{LF}$ & $1440 \mathrm{~s}$ & $1440 \mathrm{~s}$ & $1440 \mathrm{~s}$ \\
\hline
\end{tabular}

${ }^{\mathrm{a}} \mathrm{LF}$, leapfrog; PC, predict-correct; EF, Euler forward; EB, Euler backward.

${ }^{\mathrm{b}}$ After Bryan [1984]. 
Table A10. Rivers ${ }^{\mathrm{a}}$

\begin{tabular}{|c|c|c|c|c|c|}
\hline & Number Explicit & Unguaged, How? & Volume or Virtual Salt? & Temperature & Total Annual \\
\hline $\begin{array}{l}\text { AWI } \\
\text { CNF }\end{array}$ & $\begin{array}{l}13 \text { Arctic }+3 \\
\text { river routing model }\end{array}$ & proportionally & Salt sink & No & $3156 \mathrm{~km}^{3} / \mathrm{a}($ Arctic) \\
\hline GSFC & 86 & yes, randomly & Salt sink & No & $3822 \mathrm{~km}^{3} / \mathrm{a}$ (Arctic) \\
\hline ICMMG & 13 & proportionally among 13 rivers & volume & No & $3156 \mathrm{~km}^{3} / \mathrm{a}$ \\
\hline IOS & 13 & separately American, Nordic and Siberian & Salt sink & No & $3156 \mathrm{~km}^{3} / \mathrm{a}$ \\
\hline LANL & 14 Arctic, 46 global & no & Salt sink & No & $2300 \mathrm{~km}^{3} / \mathrm{a}$ \\
\hline NPS & 9 & & Salt sink & Yes & $2012 \mathrm{~km}^{3} / \mathrm{a}$ \\
\hline POL & & restore on coasts & volume & No & $\sim 1.5 \mathrm{~Sv}$ global \\
\hline UL & 20 & & Salt sink & No & $4630 \mathrm{~km}^{3} / \mathrm{a}$ \\
\hline UW & 13 & & Salt sink & No & $3156 \mathrm{~km}^{3} / \mathrm{a}$ \\
\hline
\end{tabular}

${ }^{a}$ Sources are AWI: AOMIP, GSFC: Pocklington, RasmussonMo P-E data, IOS: Prange, NPS: P.Becker + Canadian, LANL: GRDC (http://www.awibremerhaven.de/Modelling/ARCTIC/projects/rivers/rivers.html).

Table A11. Radiation

\begin{tabular}{|c|c|c|c|c|}
\hline & SW Form & Albedo $^{\mathrm{a}}$ & SW Penetration & LW Form \\
\hline AWI & daily cycle & $\mathrm{O}=.1, \mathrm{MI}=.68, \mathrm{I}=.7, \mathrm{MS}=.77, \mathrm{~S}=.81$ & & Rosati and Miyakoda (1988) \\
\hline $\mathrm{CNF}$ & coupled atmos model & & yes & coupled atmos model \\
\hline GSFC & PW, 1979 & $\mathrm{O}=.1, \mathrm{MI}=.68, \mathrm{I}=.7, \mathrm{MS}=.77, \mathrm{~S}=.81$ & no & Rosati and Miyakoda (1988) \\
\hline ICMMG & daily averaged & $\mathrm{O}=.1, \mathrm{MI}=.68, \mathrm{I}=.7, \mathrm{MS}=.77, \mathrm{~S}=.81$ & yes & Rosati and Miyakoda (1988) \\
\hline IOS & daily averaged & $\mathrm{O}=.1, \mathrm{MI}=.5, \mathrm{I}=.6, \mathrm{MS}=.7, \mathrm{~S}=.8$ & yes & Rosati and Miyakoda (1988) \\
\hline LANL & & $\mathrm{O}=.1, \mathrm{MI}=.68, \mathrm{I}=.7, \mathrm{MS}=.77, \mathrm{~S}=.81$ & yes & Rosati and Miyakoda (1988) \\
\hline POL & daily cycle & $\mathrm{O}=.1, \mathrm{MI}=.5, \mathrm{I}=.6, \mathrm{MS}=.7, \mathrm{~S}=.8$ & yes & Berliand and Berliand [1952] \\
\hline UL & daily averaged & $\mathrm{O}=.1, \mathrm{MI}=.5, \mathrm{I}=.6, \mathrm{MS}=.7, \mathrm{~S}=.8$ & yes & Rosati and Miyakoda (1988) \\
\hline UW & daily & $\mathrm{O}=.1, \mathrm{MI}=.66, \mathrm{I}=.75, \mathrm{MS}=.7, \mathrm{~S}=.84$ & yes & Rosati and Miyakoda (1988) \\
\hline
\end{tabular}

a“"O", ocean; "MI", melting ice; "I", ice; "MS", melting snow; "S", snow. Emissivities: O = .97, I = .98, S = .98.

Table A12. Air - Ocean/Ice Surface Exchange

\begin{tabular}{lccll}
\hline & Heat Exchg Coef & Moisture Exchg Coef & Momentum Transfer & Ocean Mixed Layer? \\
\hline AWI & $1.75 \mathrm{e}-3$ & $1.75 \mathrm{e}-3$ & $(1.1+.04 * \mathrm{ws}) * \mathrm{e}-3$ & none \\
CNF & $1.2 \mathrm{e}-3$ & $1.5 \mathrm{e}-3$ & coupled atmos model & MellorYamada2.5 \\
GSFC & $1.2 \mathrm{e}-3$ & $1.5 \mathrm{e}-3$ & $1.1 \mathrm{e}-3$ & integral Ri criterion \\
ICMMG & $1.2 \mathrm{e}-3$ & $1.5 \mathrm{e}-3$ & applied (NCEP) & assigned \\
IOS & $1.2 \mathrm{e}-3$ & $1.5 \mathrm{e}-3$ & $(1.1+.04 * \mathrm{ws})^{*} \mathrm{e}-3$ & KPP \\
LANL & $1.2 \mathrm{e}-3$ & $1.5 \mathrm{e}-3$ & & none \\
NPS & & & & Large and Pond [1981] \\
POL & $1.2 \mathrm{e}-3$ & $1.5 \mathrm{e}-3$ & applied (NCEP) & none \\
UL & $1.2 \mathrm{e}-3$ & $1.5 \mathrm{e}-3$ & $1.5 \mathrm{e}-3$ & none \\
UW & & & \\
\hline
\end{tabular}

Table A13. Ocean - Ice Exchange

\begin{tabular}{lllc}
\hline & Ocean-Ice Heat Exchg & Ocean-Ice FW Exchg & Ocean-Ice Momentum Exchg \\
\hline AWI & linear in oceanT-freezingT & virtual salt flux, ice at 4 ppt & quadratic, Cd $=5.5 \mathrm{e}-3$ \\
CNF & Mellor and Kantha $[1989]$ & Mellor and Kantha $[1989]$ & Mellor and Kantha $[1989]$ \\
GSFC & Mellor and Kantha $[1989]$ & Mellor and Kantha $[1989]$ & Mellor and Kantha $[1989]$ \\
ICMMG & a & virtual salt flux, ice at 4 ppt & quadratic, Cd $=5.5 \mathrm{e}-3$ \\
IOS & linear in oceanT-freezingT & virtual salt flux, ice at 4 ppt & quadratic, Cd $=5.5 \mathrm{e}-3$ \\
LANL & virtual salt flux, ice at 4 ppt & quadratic, Cd $=5.5 \mathrm{e}-3$ \\
NPS & & & quadratic, Cd $=5.5 \mathrm{e}-3$ \\
POL & linear in oceanT-freezingT & explicit freshwater and salt & quadratic, Cd $=5.5 \mathrm{e}-3$ \\
UL & linear in oceanT-freezingT & virtual salt flux, ice at 4 ppt & quadratic, Cd $=5.5 \mathrm{e}-3$ \\
UW & linear in oceanT-freezingT & virtual salt flux, ice at 4 ppt & quadratic, Cd $=5.5 \mathrm{e}-3$ \\
\hline
\end{tabular}

${ }^{\mathrm{a}} \mathrm{Heat}$, salt: ice formation in ocean (frazil) maintains temperature at or above salinity-dependent freezing temperature, up to maximum $=$ linear in ocean T-freezing T, coef 0.575 . 
Table A14. Cryosphere

\begin{tabular}{|c|c|c|}
\hline & Variables & Dynamics \\
\hline AWI & area fractions in 7 thickness bins & viscous plastic \\
\hline CNF & & elastic-viscous-plastic \\
\hline GSFC & area and thickness & general viscous \\
\hline ICMMG & area fractions in 5 thickness bins & elastic-viscous-plastic \\
\hline IOS & area, thickness & viscous plastic \\
\hline LANL & area fractions in 5 thickness bins, ice and snow energy & elastic-viscous-plastic \\
\hline NPS & area and thickness & viscous plastic \\
\hline POL & area, volume, heat and age & elastic-viscous-plastic \\
\hline UL & area, thickness & viscous plastic \\
\hline UW & area and thickness & viscous plastic \\
\hline
\end{tabular}

Table A15. Cryosphere Thermodynamics

\begin{tabular}{|c|c|c|c|c|c|}
\hline & Ice $\mathrm{T}$ Profile & Ice Conductivity & Ice Salinity & Snow T Profile & Snow Conductivity \\
\hline AWI & linear & $2.17 \mathrm{~W} / \mathrm{m} / \mathrm{K}$ & $4 \mathrm{ppt}$ & linear & $0.31 \mathrm{~W} / \mathrm{m} / \mathrm{K}$ \\
\hline $\mathrm{CNF}$ & 0 layer & $2.04 \mathrm{~W} / \mathrm{m} / \mathrm{K}$ & $5 \mathrm{ppt}$ & linear & $0.31 \mathrm{~W} / \mathrm{m} / \mathrm{K}$ \\
\hline GSFC & linear, 2 layer & $2.04 \mathrm{~W} / \mathrm{m} / \mathrm{K}$ & $5 \mathrm{ppt}$ & linear, 1 layer & $0.31 \mathrm{~W} / \mathrm{m} / \mathrm{K}$ \\
\hline ICMMG & 4 layers & $2.03 \mathrm{~W} / \mathrm{m} / \mathrm{K}$ & function & linear & $0.3 \mathrm{~W} / \mathrm{m} / \mathrm{K}$ \\
\hline IOS & linear & $2.04 \mathrm{~W} / \mathrm{m} / \mathrm{K}$ & $4 \mathrm{ppt}$ & linear & $0.31 \mathrm{~W} / \mathrm{m} / \mathrm{K}$ \\
\hline LANL & 4 layers & $2.03 \mathrm{~W} / \mathrm{m} / \mathrm{K}$ & function & linear & $0.3 \mathrm{~W} / \mathrm{m} / \mathrm{K}$ \\
\hline NPS & linear & & no & & \\
\hline POL & parabolic & $2.03 \mathrm{~W} / \mathrm{m} / \mathrm{K}$ & $4 \mathrm{psu}$ & parabolic & $0.22 \mathrm{~W} / \mathrm{m} / \mathrm{K}$ \\
\hline UL & linear & $2.04 \mathrm{~W} / \mathrm{m} / \mathrm{K}$ & $4 \mathrm{ppt}$ & linear & $0.31 \mathrm{~W} / \mathrm{m} / \mathrm{K}$ \\
\hline UW & linear & $2.17 \mathrm{~W} / \mathrm{m} / \mathrm{K}$ & $4 \mathrm{ppt}$ & linear & $0.31 \mathrm{~W} / \mathrm{m} / \mathrm{K}$ \\
\hline
\end{tabular}

Table A16. Upper Surface and Benthic

\begin{tabular}{lll}
\hline & \multicolumn{1}{c}{ Upper Surface } & Benthic Layer \\
\hline AWI & rigid lid, stream function & no \\
CNF & free surface & Nakano and Suginohara [2002] \\
GSFC & explicit free surface & yes \\
ICMMG & rigid lid, stream function & yes \\
IOS & rigid lid, stream function & no \\
LANL & implicit free surface & no \\
NPS & implicit free surface & Campin and Goosse [1999] \\
POL & explicit free surface & no \\
UL & rigid lid, stream function & no \\
UW & implicit free surface & \\
\hline
\end{tabular}

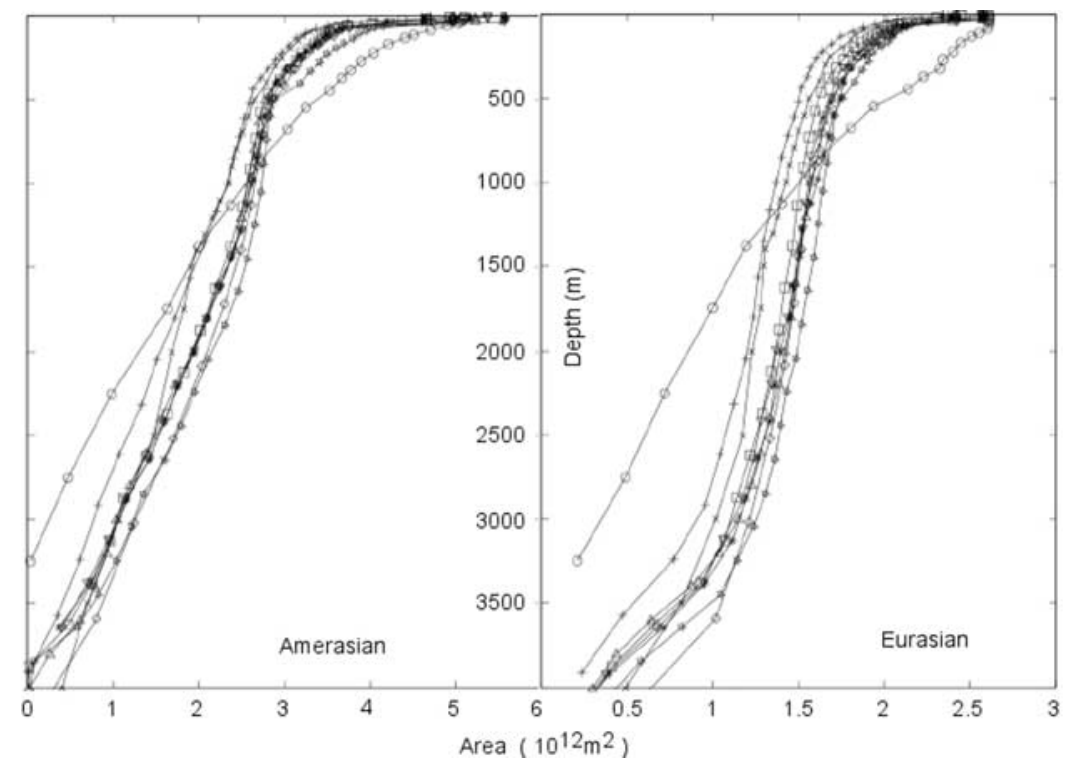

Figure A1. Lateral area $\left(1012 \mathrm{~m}^{2}\right)$ is plotted vs. depth $(\mathrm{m})$ for the Amerasian and Eurasian basins. Symbols are defined at Figure 3c. 


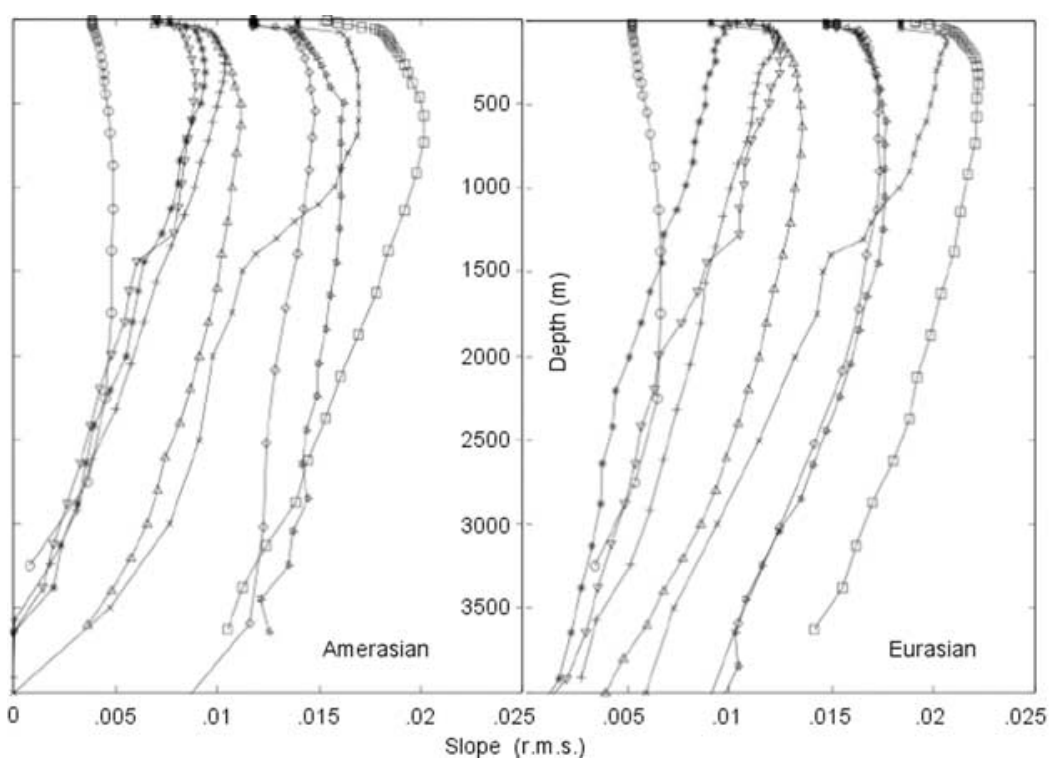

Figure A2. Root mean square slope is plotted vs. depth (m) for the Amerasian and Eurasian basins. Symbols are defined at Figure 3c.

striking differences among models' circulations which are shown to depend upon uncertain assumptions concerning the roles of unresolved eddies. In these several regards, the groups of AOMIP modelers, reflecting diverse efforts from throughout the world, are able to work together toward improving the science of Arctic modeling.

\section{Appendix A}

[42] Appendix A lists some of the models' many attributes in Tables A1-A16. Blanks occur where information was not available at the time of this publication. The global POL model is listed here for information; in the present study, POL executes a model common with IOS for the purpose of sensitivity tests reported in the Discussion section.

[43] Although many models drew their topographic data from common sources, differences among model grids, methods of assigning depths on the grids, and extent of bathymetry smoothing yield differences summarized in Table A5 and shown in Figures A1 and A2. R.m.s. slope is included to characterize typical steepness of model topography with relevance to circulation diagnostics discussed in this paper.

[44] Acknowledgments. This research is supported by the National Science Foundation Office of Polar Programs under cooperative agreements OPP-0002239 and OPP-0327664 with the International Arctic Research Center, University of Alaska Fairbanks. This research was also supported in parts by the U.S. Department of Energy, Climate Change Prediction Program, by the Center for Computational Sciences at Oak Ridge National Laboratory, by NSF/ARCSS, by the NASA Global Modeling and Analysis, Radiation Sciences, and Cryospheric Sciences Programs, and by the Russian Foundation for Basic Research. Thoughtful advice from anonymous reviewers has been incorporated throughout.

\section{References}

Aagaard, K., L. K. Coachman, and E. Carmack (1981), On the halocline of the Arctic Ocean, Deep Sea Res., Part A, 28, 529-545.

Berliand, M. E., and T. G. Berliand (1952), Measurement of the effective radiation of the Earth with varying cloud amounts, Izv. Akad. Nauk SSSR Ser. 1.
Bryan, K. (1984), Accelerating the convergence to equilibrium of oceanclimate models, J. Phys. Oceanogr., 14, 666-673.

Bryan, K., and L. J. Lewis (1979), A water mass model of the World Ocean, J. Geophys. Res., 84, 2503-2517.

Campin, J.-M., and H. Goosse (1999), Parameterization of density-driven downsloping flow for a coarse-resolution ocean model in $\mathrm{z}$-coordinate, Tellus, Ser. A, 51, 412-430.

Environmental Working Group (EWG) (1997), Arctic Climatology Project [CD-ROM], edited by L. Timokhov and F. Tanis, Natl. Snow and Ice Data Cent., Boulder, Colo.

Environmental Working Group (EWG) (1998), Arctic Climatology Project [CD-ROM], edited by L. Timokhov and F. Tanis, Natl. Snow and Ice Data Cent., Boulder, Colo.

Gargett, A. E., and G. Holloway (1984), Dissipation and diffusion by internal wave breaking, J. Mar. Res., 42, 15-27.

Hofmann, M., and M. A. Morales Maqueda (2006), Performance of a second-order moments advection scheme in an Ocean General Circulation Model, J. Geophys. Res., 111, C05006, doi:10.1029/2005JC003279.

Holloway, G. (2004), From classical to statistical ocean dynamics, Surv. Geophys., 25, 203-219.

Holloway, G., and A. Proshutinsky (2007), Role of tides in Arctic ocean/ice climate, J. Geophys. Res., doi:10.1029/2006JC003643, in press.

Hunke, E., and M. Holland (2007), Global atmospheric forcing data for Arctic ice-ocean modeling, J. Geophys. Res., doi:10.1029/2006JC003640, in press.

Ishizaki, H., and T. Motoi (1999), Reevaluation of the Takano-Oonishi scheme for momentum advection on bottom relief in ocean models, J. Atmos. Oceanic Technol., 16, 1994-2010.

Johnson, M., S. Gaffigan, E. Hunke, and R. Gerdes (2007), A comparison of Arctic Ocean sea ice concentration among the coordinated AOMIP model experiments, J. Geophys. Res., doi:10.1029/2006JC003690, in press.

Kalnay, E., et al. (1996), The NCEP/NCAR 40-Year Reanalysis Project, Bull. Am. Meteorol. Soc., 77, 437-495.

Karcher, M., F. Kauker, R. Gerdes, E. Hunke, and J. Zhang (2007), On the dynamics of Atlantic Water circulation in the Arctic Ocean, J. Geophys. Res., doi:10.1029/2006JC003630, in press.

Large, W. G., and S. Pond (1981), Open ocean momentum flux measurements in moderate to strong winds, J. Phys. Oceanogr., 11, 324-336.

Leonard, B. P., M. K. MacVean, and A. P. Lock (1993), Positivity-preserving numerical schemes for multidimensional advection, NASA Tech. Memo., 106055, ICOMP-93-05.

Lin, S.-J., W. C. Chao, Y. C. Sud, and G. K. Walker (1994), A class of van Leer-type transport schemes and its application to the moisture transport in a general circulation model, Mon. Weather Rev., 122, $1575-1593$.

Martin, T., and R. Gerdes (2007), Sea ice drift variability in AOMIP models and observations, J. Geophys. Res., doi:10.1029/2006JC003617, in press. Melling, H., and E. L. Lewis (1982), Shelf drainage flows in the Beaufort Sea and their effect on the Arctic Ocean pycnocline, Deep Sea Res., Part A, 29, 967-985. 
Mellor, G. L., and L. H. Kantha (1989), An ice-ocean coupled model, J. Geophys. Res., 94, 10,937-10,954.

Merryfield, W. J., and R. B. Scott (2007), Bathymetric influence on mean currents in two high-resolution near-global ocean models, Ocean Modell., $16,76-94$.

Morales Maqueda, M. A., and G. Holloway (2006), Second Order Moment advection scheme applied to Arctic Ocean simulation, Ocean Modell., 14, $197-221$

Nakano, H., and N. Suginohara (2002), Effects of bottom boundary layer parameterization on reproducing deep and bottom waters in a World Ocean model, J. Phys. Oceanogr., 32, 1209-1227.

Nazarenko, L., G. Holloway, and N. Tausnev (1998), Dynamics of transport of 'Atlantic signature' in the Arctic Ocean, J. Geophys. Res., 103, $31,003-31,015$.

Polyakov, I. (2001), An eddy parameterization based on maximum entropy production with application to modeling of the Arctic Ocean circulation, J. Phys. Oceanogr., 31, 2255-2270.

Polyakov, I., D. Walsh, I. Dmitrenko, R. L. Colony, and L. A. Timokhov (2003), Arctic Ocean variability derived from historical observations, Geophys. Res. Lett., 30(6), 1298, doi:10.1029/2002GL016441.

Prather, M. C. (1986), Numerical advection by conservation of secondorder moments, J. Geophys. Res., 91(D6), 6671-6681.

Proshutinsky, A., et al. (2001), The Arctic Ocean Model Intercomparison Project (AOMIP), Eos Trans. AGU, 82, 637-644.

Proshutinsky, A., et al. (2005), Arctic Ocean study: Synthesis of model results and observations, Eos Trans. AGU, 86(40), 368.

Rudels, B., L. G. Anderson, and E. P. Jones (1996), Formation and evolution of the surface mixed layer and halocline of the Arctic Ocean, J. Geophys. Res., 101(C4), 8807-8822.

Shimada, K., M. Itoh, S. Nishino, F. McLaughlin, E. Carmack, and A. Proshutinsky (2005), Halocline structure in the Canada Basin of the Arctic Ocean, Geophys. Res. Lett., 32, L03605, doi:10.1029 2004GL021358.

Steele, M., and T. Boyd (1998), Retreat of the cold halocline layer in the Arctic Ocean, J. Geophys. Res., 103, 10,419-10,435.

Steele, M., W. Ermold, G. Holloway, S. Häkkinen, D. M. Holland, M. Karcher, F. Kauker, W. Maslowski, N. Steiner, and J. Zhang (2001), Adrift in the Beaufort Gyre: A model intercomparison, Geophys. Res. Lett., 28, 2835-2838.

Steiner, N., et al. (2004), Comparing modeled streamfunction, heat and freshwater content in the Arctic Ocean, Ocean Modell., 6, 265-284.
Swift, J. H., K. Aagaard, L. Timokhov, and E. G. Nikiforov (2005), Longterm variability of Arctic Ocean waters: Evidence from a reanalysis of the EWG data set, J. Geophys. Res., 110, C03012, doi:10.1029/ 2004JC002312.

Uotila, P., et al. (2006), An energy-diagnostics intercomparison of coupled ice-ocean arctic models, Ocean Modell., 11, 1-27.

Woodgate, R. A., K. Aagaard, R. D. Muench, J. Gunn, G. Bjork, B. Rudels, A. T. Roach, and U. Schauer (2001), The Arctic Ocean Boundary Current along the Eurasian slope and the adjacent Lomonosov Ridge: Water mass properties, transports and transformations from moored instruments, Deep Sea Res., Part I, 48, 1757-1792.

Yang, J. (2005), The Arctic and subarctic ocean flux of potential vorticity and the Arctic Ocean circulation, J. Phys. Oceanogr., 35, 2387-2407.

Zhang, J., and M. A. Steele (2007), Effect of vertical mixing on the Atlantic Water layer circulation in the Arctic Ocean, J. Geophys. Res., doi:10.1029/2006JC003732, in press.

F. Dupont, Quebec-Ocean, Université Laval, Sainte-Foy, QC, Canada G1K7P4.

E. Golubeva and G. Platov, Institute of Computational Mathematics and Mathematical Geophysics, Siberian Branch of Russian Academy of Sciences, 630090 Novosibirsk, Russia.

S. Häkkinen, NASA Goddard Space Flight Center, Greenbelt, MD 20771, USA.

G. Holloway, Institute of Ocean Sciences, Department of Fisheries and Oceans, Sidney, BC, Canada V8L4B2.

E. Hunke and M. Maltrud, Climate, Ocean and Sea Ice Modeling Program, Los Alamos National Laboratory, Los Alamos, NM 87545, USA.

M. Jin and J. Wang, International Arctic Research Center, University of Alaska Fairbanks, Fairbanks, AK 99775, USA.

M. Karcher and F. Kauker, Alfred Wegener Institute for Polar and Marine Research, D-27515 Bremerhaven, Germany.

W. Maslowski and D. Stark, Department of Oceanography, Naval Postgraduate School, Monterey, CA 93943, USA.

M. A. Morales Maqueda, Proudman Oceanographic Laboratory, 6 Brownlow Street, Liverpool L3 5DA, U.K.

M. Steele and J. Zhang, Applied Physics Laboratory, University of Washington, Seattle, WA 98105-6698, USA

T. Suzuki, Frontier Research Center for Global Change, Yokohama, Kanagawa 236-001, Japan. 